\title{
Bibliografía comentada del estado de Quintana Roo
}

Lorena Careaga Viliesid

\section{Introduccion}

Curiosamente, la bibliografía del estado de Quintana Roo es abundante, pero al mismo tiempo dispersa, en gran parte agotada y muy poco difundida. Hasta 1979 , se ignoraba prácticamente el caudal de información que existía fuera de su territorio. Muchas obras publicadas en el extranjero jamás llegaron al estado y, en realidad, no es sino hasta 1974 , fecha en que el territorio federal se convierte en estado libre y soberano, cuando los propios quintanarroenses empiezan a interesarse en su historia, en la naturaleza que los rodea y en el desarrollo futuro de su entidad.

Hasta que se creó el Fondo de Fomento Editorial del Gobierno del Estado de Quintana Roo, a principios de 1979, no existía una difusión sistemática de la historia de Quintana Roo, más que, tal vez, a través de pequeños artículos en periódicos locales, o de obras de autores quintanarroenses que circulaban a un nivel muy. reducido. Se desconocía tanto sobre su historia, como sobre cualquier otro tema que le atañera.

Tampoco existía un solo organismo, privado o estatal, que unificara la investigación y difusión de las obras sobre Quintana Roo, asi las ya publicadas como las que se estaban elaborando cada vez con mayor interés. Actualmente el Instituto Quintanarroense de Cultura de Chetumal está iniciando un proyecto de gran utilidad para el conocimiento y difusión de la bibliografía sobre Quintana Roo, que consiste en la recopilación de material bibliográfico y de archivos para constituir un acervo lo más completo y actualizado posible sobre su historia.

La primera bibliografia de Quintana Roo fue publicada en 1937 por Elena Gómez Ugarte y Aurora Pagaza, con el título de Bibliografia Sumaria de Quintana Roo. Incluye una enorme cantidad de obras generales sobre la península de Yucatán y las más importantes sobre Quintana Roo hasta esos años. Desgraciadamente carece de datos bibliográficos completos y tiene varios errores en cuanto a autores y títulos. Se trató de corregir tales errores en la Bibliografia General de Quinta Roo, recopilada por Lorena Careaga Viliesid y publicada por el Fondo de Fomento Editorial en 1979. Es una bibliografía actualizada a esa fecha, más centrada que la anterior en lo que es propiamente el estado y con datos de localización y fuente en la mayoría de las obras. La recopilación se llevó a cabo primordialmente en la Biblioteca del Congreso, en Washington, D. C., donde se encuentra reunido el $80 \%$ de las obras existentes sobre Quintana Roo en particular, y sobre la peninsula de Yucatán en general, especialmente obras clásicas, del siglo pasado y contemporáneas agotadas, además de los estudios más recientes que sobre Quintana Roo se han realizado en Estados Unidos.

En México, las principales bibliotecas de consulta son la Nacio- 
nal, la de Antropología e Historia y la de El Colegio de México. En Mérida, son fundamentales la Biblioteca General Manuel Cepeda Peraza, la Hemeroteca Pino Suárez y la Biblioteca Carlos R. Menéndez. Finalmente, como se dijo, en la ciudad de Chetumal se localiza el Instituto Quintanarroense de Cultura, que se encuentra reuniendo un importante acervo en la llamada Sala Bibliográfica Chilam Balam de Tusik.

A partir de 1979, el Fondo de Fomento Editorial inició la publicación y reedición de varias obras sobre Quintana Roo, a la vez que empezaron a aparecer numerosas publicaciones oficiales, editadas por las secretarias de Agricultura y Recursos Hidráulicos, de Programación y Presupuesto y de Educación Pública principalmente. Se inició también una difusión más amplia de los estudios que diversos organismos estaban haciendo, como el Centro Regional del Sureste del INAH. el Centro de Investigaciones de Quintana Roo, A. C. (CIQRO) y el Centro de Investigaciones y Estudios Superiores en Antropologia Social (CIESAS) en su rama del sureste, entre otros.

Hoy en día, la bibliografía más completa y actualizada sobre Quintana Roo se encuentra en el Instituto de Investigaciones Dr. José Ma. Luis Mora. De ella, la presente bibliografía comentada es sólo una mínima parte, y abarca desde 1847 aproximadamente, fecha en que se inicia la guerra de Castas de Yucatán, hasta la actualidad, concretamente 1974, año en que, como se ha dicho, Quintana Roo se convierte en estado. Las obras que se incluyen en este trabajo se consideran básicas para la reconstrucción histórica de Quintana Roo en la etapa mencionada y podrian agruparse en siete grandes temas o apartados:

1) Obras generales sobre la península de Yucatán, ya que Quintana Roo no existía como tal en el siglo pasado y surge a la vida como territorio federal en 1902 . En los respectivos comentarios se hace hincapié en la información que contienen sobre Quintana Roo, o bien en el interés que puedan tener para su estudio.

2) Obras sobre diversos temas de la guerra de Castas (antecedentes, causas, inicios, fundación de Chan Santa Cruz, cacicazgos independientes, relaciones con Belice, etc.), acontecimiento histórico que dominó la segunda mitad del siglo XIX en Yucatán y que resulta primordial en el surgimiento de Quintana Roo como entidad federal, además de que su actual población maya es heredera de la tradición de la lucha armada.

3) Obras que tratan especificamente de Belice y del problema diplomático y fronterizo entre México y esta antigua colonia británica que, además de tener relación directa con los antecedentes, creación y desarrollo del territorio federal de Quintana Roo, es actualmente uno de nuestros países vecinos en la frontera sur.

4) Obras especificas sobre la historia de Quintana Roo en este siglo, desde su creación en 1902 , hasta que se convierte en estado libre y soberano.

5) Obras generales que tratan sobre otros aspectos fundamentales de Quintana Roo, como son su geografía, economía y etnografía, y que complementan los textos históricos.

6) Crónicas y diarios de viajeros y exploradores nacionales y extranjeros que visitaron Quintana Roo, tanto en el siglo pasado como en la época contemporánea. 
7) Bibliografías y guías de archivos.

No se han comentado, y por lo tanto no se incluyen aqui, las obras de tipo estadístico, como los informes de gobierno, prontuarios, censos y estudios de dependencias oficiales. Tampoco se incluye el material de archivo, por ser extremadamente abundante, aun cuando las referencias se encuentran recopiladas en el Instituto de Investigaciones Dr. José Ma. Luis Mora. Cabe aclarar, finalmente, que en algunas fichas se incluyen comentarios del historiador norteamericano Howard F. Cline, especializado en la historia social de Yucatán del siglo pasado.. Los comentarios han sido tomados de su bibliografía selecta y comentada sobre la guerra de Castas, publicada por primera vez en los apéndices de la obra clásica sobre etnografía de Quintana Roo, The Maya of East Central Quintana Roo, de Alfonso Villa Rojas (1945), traducida al castellano en 1978 por el Instituto Nacional Indigenista, con el título de Los elegidos de Dios.

\section{Obras generales sobre la peninsula de Yucatân}

BCWDC Acereto, Albino, "Historia Política desde el descubriF1376 miento europeo hasta 1920", Enciclopedia Yucatav. nense, México, Gobierno del Estado de Yucatán, 1947 BIM

C $\stackrel{C}{972.65}$ ENC. y 1947 , vol. 3 , p. 5-388.

Como su título indica, este amplio artículo es una reseña histórica de los hechos políticos que han afectado a Yucatán desde el descubrimiento de la península, hasta el año 1920. Presenta datos importantes sobre la Colonia, la participación de Yucatán en las guerras de Independencia, los conflictos entre centralistas y federalistas, que caracterizaron una buena parte del siglo XIX, la guerra de Castas, la separación de Campeche, la creación del territorio de Quintana Roo, terminando con los sucesos acaecidos en Yucatán durante la Revolución de 1910. Cuenta con una bibliografia básica bastante pobre y sin datos de publicación completos.

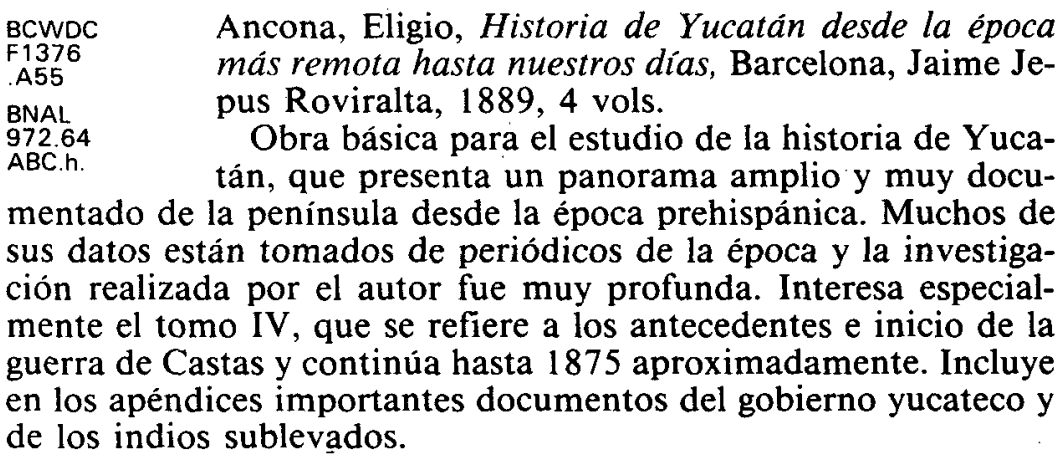

BCWDC

F1251

.A99

COLMEX

972.63

A995 $\mathrm{m}$

Aznar Barbachano, Tomás y Juan Carbó, Memoria sobre la conveniencia, utilidad y necesidad de erigir constitucionalmente en estado de la Confederación Mexicana el antiguo distrito de Campeche, constituido de hecho en estado libre y soberano desde mayo de 1848 en virtud de los convenios de división territorial que celebró 
con el estado de Yucatán, México, Ignacio Cumplido, 1861, $202 \mathrm{p}$.

En esta obra se encuentra información relevante sobre los reajustes que sufrió la península de Yucatán a partir de la segunda etapa de la guerra de Castas (1850-1865). Contiene en los apéndices importantes documentos, tablas de población, cuadros estadísticos y dos mapas. Son importantes para Quintana Roo los apéndices que se refieren a los limites entre Yucatán y Campeche, la irrupción de indios orientales en el estado de Campeche a fines de 1860 , los sucesos en Valladolid en enero de 1847 , y la opinión del gobierno de Yucatán sobre la deportación de mayas rebeldes a Cuba.

BCWDC

F1376

.B22

BNAL

972.64

BAQ.e

1871

Baqueiro, Serapio, Ensayo histórico sobre las revoluciones de Yucatán desde el año 1840 hasta 1864, Mérida, Manuel Heredia Argüelles, 1878-1879, 2 vols.

Al igual que la obra de Eligio Ancona, ésta resulta básica para la comprensión de la historia de Yucatán en una de las etapas más importantes: la lucha entre centralistas y federalistas, $\mathrm{y}$, paralelamente, la iniciación y recrudecimiento de la guerra de Castas. La primera edición es de 1878 y contiene gran cantidad de datos sobre las campañas políticas y militares, y sobre personalidades de la época en Yucatán. En los apéndices se reproducen numerosos documentos originales que complementan el texto. En palabras de Howard Cline, Baqueiro refleja el punto de vista de un partidario de Mérida en contra de Campeche, y el de un "liberal progresista" opuesto al conservadurismo y al clericalismo.

COLMEX

972.63

B225r

Baranda, Joaquín, Recordaciones históricas, México, La Europea, 1907, 2 vols.

Esta obra, escrita por un político, no un historiador, es interesante en cuanto a que presenta el punto de vista de Campeche en el conflicto con Mérida. Además, relaciona hechos ocurridos en la península con la política del centro de México, lo cual da al lector una visión más amplia de esta etapa en que la guerra de Castas llega a un punto culminante y Campeche se constituye en entidad federativa independiente de Yucatán.

BCwOC Cantón Rosado, Francisco, Datos y Documentos relaF1231 tivos a la vida militar y politica del Sr. Gral. Brigadier .58 Don Francisco Cantón, Mérida, Compañía TipográCOLMEX fica Yucateca, 1930, $225 \mathrm{p}$.

972 .

.08

C2326d

El autor recopila y ordena los documentos del archivo de su padre, quien fuera gobernador de Yucatán en 1901, año en que se creó el territorio de Quintana Roo. La obra se inicia con una detallada biografía del Gral. Cantón, para continuar con la reproducción de numerosas cartas, muchas de ellas inéditas, sobre sus actividades políticas y militares. Entre dichas cartas destaca la correspondencia intercambiada entre Cantón y Porfirio Díaz sobre la creación del territorio de Quintana Roo, a través de la cual Cantón trata de hacer ver al presidente lo inconveniente de dicha medida para la economía y desarrollo futuros de Yucatán. 
LAL/TU Rare book case 972.64

C 3522

BNAL

$\mathrm{C}$

972.64003

CAS.d.

Castillo, Gerónimo del, Diccionario histórico, biográfico y monumental de Yucatán, Mérida, 1866, $315 \mathrm{p}$. (2a. ed., 1886)

Se trata de una obra de consulta en forma de diccionario, de la cual sólo se publicó el volumen uno, llegado hasta la letra D. Como su título indica, proporciona información sobre hechos históricos, personajes, lugares y monumentos de la península de Yucatán. El autor fue el editor en 1846 de la revista llamada Registro Yucateco y varios de los artículos que aparecieron originalmente en ella se encuentran reproducidos en este diccionario. Destacan "La bahía de la Ascensión", de José Joaquín de Torres; "Bacalar" por Miguel Acevedo; "La montaña de Bacalar", por José Joaquín de Torres; "Derrotero de las costas de Yucatán", por Miguel Molas; "La isla de Cozumel", por Martín Francisco Peraza; "Las cruces de Cozumel", por Justo Sierra O'Reilly, y varios comentarios más sobre Cabo Catoche, Chichanhá y otros lugares del actual Quintana Roo.

BCWDC Cline, Howard F., "The Sugar Episode in Yucatan, HC161

.1585

COLMEX

330.98

$\ln 61$ 1825-1850", Inter American Economic Affairs, vol. 1, núm. 4, 1948, p. 79-100.

En este artículo, Cline pretende demostrar que el crecimiento de la industria azucarera en Yucatán fue uno de.los factores más importantes en el estallido de la guerra de Castas en 1847. Cline afirma que el avance de las plantaciones dedicadas al cultivo del azúcar hacia la zona oriental de la peninsula, absorbiendo poblados campesinos, encendió una chispa imposible de detener. Analiza, además, algunos elementos centrales de la evolución de dicha industria y los problemas que enfrentó en su desarrollo, hasta quedar prácticamente anulada durante la guerra de Castas.

BCwDC Cline, Howard F., "The Henequen Episode in Yuca.1585 COLMEX 330.98 tan", Inter American Economic Affairs, vol. 2, núm. 2,1948 , p. $30-51$.

$\ln 61$

Cline analiza en este artículo los orígenes y el desarrollo de la industria henequenera en Yucatán, la cual ocupó el lugar preponderante en la economía yucateca que se pensó ocuparia la industria del azúcar. El henequén sirvió, además, en opinión del autor, como un "parachoques" económico durante y después de la guerra de Castas. Se analizan los antecedentes del cultivo del henequén en la época colonial, las caracteristicas de la planta, los métodos de cultivo e industrialización, y su desarrollo desde 1850 hasta alcanzar su auge en 1880 , con la modernización del puerto de Progreso, que sustituyó al de Sisal a fines de la década de 1860 .

$\begin{array}{lll}\text { BCWDC } & \text { COLMEX } & \text { De Armond, Louis, “Justo Sierra } \\ \text { F1401 } & 980 & \text { O'Reilly and Yucatecan-U.S. Relations, } \\ \text {.H66 } & \text { H6731 } & \text { 1847-1848", Hispanic American Histo- } \\ \text { BNAL } & & \text { rical Review, vol. 31, núm. 3, agosto, } \\ 980.005 & & 1951, \text { Durham, p. 420-436. }\end{array}$

Artículo que analiza los conflictos entre las facciones centralistas y federalistas de Yucatán desde 1846, y el enfrentamiento entre las ciudades de Mérida y Campeche, cuyos políticos utilizaron 
a los indios mayas en la lucha armada, dando pie, un año más tarde, al estallido de la guerra de Castas. En este marco se describe la misión de Justo Sierra O'Reilly, nombrado por el gobernador Barret como "comisionado y representante" del gobierno de Yucatán, para pedir ayuda a los Estados Unidos en contra de los mayas sublevados, y las razones por las cuales fracasó dicha misión.

BCwDC Figueroa, Domenech, J., ed., Guia general descriptiva F1215

$\mathrm{F47}$

v. 2

1899

BNAL

917.2058 de la República Mexicana, México, Ramón de S.N. Araluce, 1899, 2 vols.

Guía con datos geográficos, históricos y estadistiFIG.9. cos sobre México, además de un triple directorio del comercio, la industria y los servicios públicos, incluyendo autoridades, oficinas públicas, abogados, médicos, hacendados, correos, telégrafos, ferrocarriles, etc. En el volumen II, dentro del capítulo titulado "Estado de Yucatán" (p. 737-752), se encuentran importantes datos sobre el actual Quintana Roo: la isla tiburonera de Holbox, Cabo Catoche, Isla Mujeres, Cozumel, el puerto chiclero de Vigía Chico, el río Hondo y los límites y relaciones con Belice, etcétera.

COLMEX Mediz Bolio, Antonio, La desintegración de Yucatán 972.64 M49110 auténtico. Proceso histórico de la reducción del terririda, s. e., 1974,54 p. torio yucateco a sus limites actuales, 1821-1902, Mé-

Los tres primeros capitulos de la obra fueron publicados en la revista $A s i$ de la ciudad de México, el 7, 14 y 18 de diciembre de 1942. Los dos últimos aparecieron durante el mes de junio de 1954 en el Diario del Sureste de Mérida. El autor desea contribuir con dichos artículos a los estudios sobre la creación del territorio de Quintana Roo y a las posibilidades juridicas, sociales, económicas y políticas en que pudiera fundarse una solicitud de reincorporación al estado de Yucatán.

BCwDC Mena Brito, Bernardino, Historia de las desmembraF1376 M53

BNAL

972.64 ciones del estado de Yucatán efectuadas por el Gobierno Nacional: el Petén, Belice, Campeche y QuinMEN.h. tana Roo, México, Botas, 1962, 62 p.

"El Territorio de Quintana Roo cuesta mucho dinero al erario nacional y es un semillero de inmoralidades que afectan a Yucatán". Con este título se inicia un capítulo del libro en el que el autor considera que la creación del territorio de Quintana Roo "constituye la injusticia más grande y sangrante cometida contra el pueblo yucateco", al reducir la extensión del estado de Yucatán y privarlo de la riqueza de recursos naturales de la zona oriental. Denuncia y protesta en contra de este hecho, y realiza un análisis posterior de los conflictos de límites entre Yucatán y Quintana Roo y de las subsecuentes supresiones y recreaciones del territorio, en detrimento de los intereses yucatecos. vols. 
En opinión de Howard Cline, se trata de una obra valiosa para referencias inmediatas y representa una investigación honesta y competente, limitada tan sólo por una selección de fuentes muy reducida, en su mayoría de tipo político y oficial. Omite también importantes tendencias sociales y económicas y su relación con los sucesos de antes y de durante la guerra de Castas.

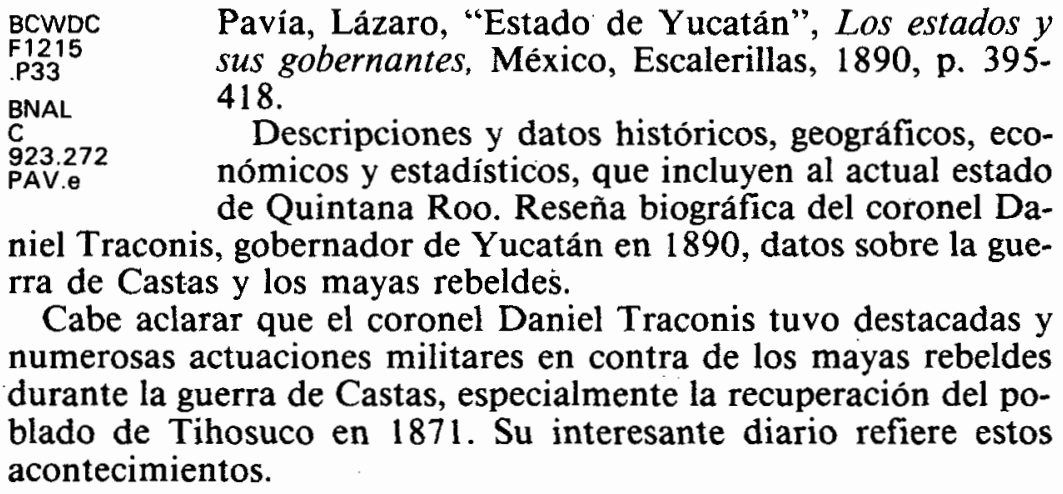

BNAL Pérez Galaz, Juan de Dios, Situación estadistica de P72.64 Yucatân en 1851, México, Secretaria de Gobernación, $1948,183 \mathrm{p}$.

Documentos pertenecientes a la memoria que el secretario del Despacho de Gobernación presentó a las honorables Cámaras del estado de Yucatán el $1^{\circ}$ de enero de 1852, acerca de la situación económica y demográfica de Yucatán en esa época. Contiene datos sobre Yucatán, Campeche y el actual Quintana Roo, así como sobre la jurisdicción eclesiástica de la península, que llegó a abarcar hasta el estado de Tabasco.

BCwDC Regil, José Maria y Alonso M. Peón, "Estadística de .567 Yucatán", Boletín de la Sociedad Mexicana de GeoBNAL grafia $y$ Estadistica, época 1, vol. 3, 1852, p. 237 336.

910.6272

SOC.b

Howard Cline considera esta obra como un estudio social y económico de primera clase. Escrito hacia 1846, es absolutamente indispensable su consulta para entender la situación de Yucatán en vísperas de la guerra de Castas. Originalmente, esta obra fue preparada por Regil como un informe oficial, y fue corregida y aumentada por Peón, logrando un estudio lúcido y verosímil de los recursos humanos y materiales de la península, incluyendo documentos comparativos sobre su historia y su geografía. Incluye también numerosos cuadros y tablas de interés.

$\begin{array}{ll}\text { BCWDC } & \text { BNAL } \\ \text { F1234 } & 327.73098 \\ \text { U565 } & \text { MAN.d } \\ \text { US Congress } & \\ \text { Senate In- } & \text { COLMEX } \\ \text { vestigation } & 327.7308 \\ \text { on Mexican } & \text { M284d } \\ \text { Affairs. } & \end{array}$

Senado de los Estados Unidos, Executive Documents, 30th. Congress, 1 st. session, 1847-1848, vol. 5 y 6 , documentos $40,42,43,45$ y 49 .

Cada documento, según Howard Cline, es una colección de trabajos relevantes: informes formales e informales, cartas, reimpresiones de artículos periodísticos, etc. Constituyen una mina de información 
sobre los asuntos yucatecos de 1847 y 1848 . Algunos de estos documentos han sido publicados en: William R. Manning, Diplomatic Correspondence of the U.S.: Interamerican Affairs, 1831-1860, Washington, Carnegie Endowment for International Peace, 12 vols. 1932-1939. Para Yucatán, consultar el vol. 8.

BCWDC Shattuck, George C., The Peninsula of Yucatan, AS32. .C280p BNAL 917.264 Washington, Carnegie Institution of Washington, Publication 431, 1933, 576 p.

SHA.p.

La obra contiene datos generales sobre geogratía, demografía, geologia, botánica y zoología. Datos históricos desde la época prehispánica hasta la fecha en que el autor visitó la península de Yucatán, hacia 1926. Datos antropológicos y etnográficos de los mayas, e información sobre las acciones del gobierno federal y estatal, y sobre algunas ciudades importantes, como Mérida, Campeche, Valladolid y Payo Obispo (Chetumal), Quintana Roo. El capítulo noveno se titula "La vida en los bosques de Quintana Roo". Incluye interesantes descripciones de la exportación chiclera, la colonia Santa María (hoy Leona Vicario) y los indios de Santa Cruz de Bravo. Abarca también estudios generales de tipo médico, como las enfermedades más comunes, grupos sanguíneos y condiciones sanitarias. BCwDC Sierra O'Reilly, Justo, Diario de nuestro viaje a EsF1376
S64 tados Unidos. La pretendida anexión de Yucatán,

BNAL

972.6405 México, Antigua Librería Robredo, 1938, 125 p.

SIE.d.

En este diario, el autor relata con detalle lo que aconteció durante su llamada misión en Estados Unidos, durante la que intentó obtener el apoyo del gobierno norteamericano en favor de los criollos yucatecos, en su lucha contra los mayas rebeldes. Contiene, además del texto, reproducciones de pinturas y bosquejos de batallas habidas durante la guerra de Castas, así como un apéndice que es obra de Héctor Pérez Martínez, titulada "Orígenes económicos y sociales de la guerra de Castas". Se publicó un segundo tomo posteriormente, que continúa el relato del viaje.

COLMEX 330.97264 s939e

Suárez Molinas, Víctor M., La evolución económica de Yucatán a través del siglo XIX, Mérida, Universidad de Yucatán, 1977. 2 vols.

Se analiza aqui la economía del estado de Yucatán desde el inicio de la época independiente, hasta fines del siglo XIX. Abarca la siguiente temática: visión de conjunto; geografía e historia; actividades agropecuarias; actividades industriales; actividades comerciales; comunicaciones y transportes; moneda, banca y crédito; apéndices documentales. Cuenta también con una muy buena bibliografía comentada sobre el tema.

BCWDC Strickon, Arnold, "Hacienda and plantation in YucaE51

A45

COLMEX

970.1

A 512 El autor hace un análisis de las plantaciones azucareras que florecieron en la zona fronteriza entre Yucatán y lo que hoy son las selvas de Quintana Roo. En dicha región, de hecho se

tan: a historical-ecological consideration of the folkurban continuum in Yucatan", América Indigena, vol. 25, núm. 1, 1965, México, p. 35-63.

El autor hace un análisis de las plantaciones azuca- 
inició la guerra de Castas en 1847 , como una reacción, en gran parte, a estas plantaciones que iban despojando poco a poco de sus tierras a los campesinos mayas libres aún del peonaje de las haciendas.

\section{Aspectos diversos de la guerra de Castas}

BCWDC Ay, Manuel Antonio, De la guerra de Castas, causa ${ }_{\mathrm{F} 9}$ de Manuel Antonio $A y$, primer indio rebelde maya fusilado en Valladolid el 30 de julio de 1847, Mérida,

Asociación Cívica Yucateca, 1956, 42 p.

Relación del juicio en el que se dictaminó la culpabilidad de Manuel Antonio Ay en la rebelión contra el gobierno de Yucatán, al encontrársele una carta incriminatoria en la que se hablaba de un ataque al pueblo de Tihosuco por los caciques Jacinto Pat y Cecilio Chi, líderes de los mayas rebeldes. Declaraciones del acusado, de testigos y sentencia final. El reo fue condenado a morir fusilado, acto que presenciaron muchos mayas y que se considera constituye un antecedente inmediato de la sublevación de 1847 .

BNAL Bartolomé, Miguel Alberto y Alicia M. Barabas, La 301.29726 resistencia maya. Relaciones interétnicas en el oriente BAR.r de la península, Mérida, INAH. Centro Regional del Sureste, 1976, 133 p. (Colección Científica).

Análisis de la guerra de Castas y, en especial, de la creación y desarrollo de Chan Santa Cruz como parte de una lucha étnica en la que los mayas recuperan su identidad histórica. Continúa con un estudio de la situación actual de las comunidades rebeldes y de la integración a la que se ven forzados como parte del Quintana Roo de hoy. Se lleva a cabo una caracterización de algunos aspectos sobresalientes de las relaciones interétnicas actuales. El objeto de dicho análisis es reforzar la perspectiva del pluralismo cultural como sistema, "no sólo ideológico, sino político-organizativo, que permita el establecimiento de un diálogo interétnico que reemplace al actual monólogo del dominador".

CIESAS Chi Poot, María Bonifacia, Medio siglo de resistencia Ch.p. armada maya; fuentes documentales, México, SEP, CIESAS, $1982,319 \mathrm{p}$.

La autora se propone realizar un breve análisis dialéctico de los hechos que caracterizaron el inicio y los primeros años de la guerra de Castas, a partir de las fuentes escritas que dejaron los mayas y las autoridades civiles, militares y eclesiásticas de Yucatán. Se trata de la transcripción de dichos documentos, en su mayoría en maya, con el objeto de que sean conocidos especialmente por las comunidades mayas de la actualidad y puedan hacer su propia interpretación de una historia en la que son los principales protagonistas.

BCWDC

E11

A4

COLMEX

970.05

A5 12

Clegern, Wayne M., "British Honduras and the Pacification of Yucatán", The Americas, vol. 18, enero, 1962, Washington, p. 243-254.

Artículo sumamente revelador y sugerente, que analiza la ultima campaña del gobierno federal contra los mayas rebeldes de Chan Santa Cruz como un esfuerzo con- 
junto del porfirismo y del gobierno británico en Belice para controlar definitivamente una zona fronteriza en conflicto. Presenta la creación del territorio de Quintana Roo como parte fundamental de ese esfuerzo de pacificación y de negociación de los límites fronterizos.

BCWDC Cline, Howard F., Related Studies in Early Nine${ }_{1486}$ teenth Century Yucatecan Social History, Chicago, N.32 F Microfilm Collection of Manuscripts on Middle American Cultural Anthropology, núm. 32, University of Chicago Library, 1950.

Este manuscrito constituye la base de la tesis doctoral de Cline, titulada Regionalism and Society in Yucatân, 1821-1847 (Harvard, 1847) y consiste de tres partes: a) "War of the Castes and the Independent Indian States of Yucatan"; b) "The War of the Castes and its consequences"; c) "Regionalism and Society in Yucatan, 1825-1847: A Study of Progressivism and the Origins of the Caste War'. Es una fuente fundamental para los antecedentes de la guerra de Castas y para los cacicazgos independientes.

BCWDC González Navarro, Moisés, "La guerra de Castas de F1201 Yucatán y la venta de mayas a Cuba", Historia Mexicana, vol. 18, núm. 1, jul.-sept., 1968, México, El H673 Colegio de México, p. 11-34.

Análisis de las condiciones de trabajo y servidumbre de los peones de las haciendas yucatecas prevalecientes después de la Independencia. Legislación de las mismas al inicio de la guerra de Castas, suprimiendo prácticamente todos los derechos de los trabajadores mayas y aumentando los impuestos que debian pagar. Desarrollo de la guerra en 1848 , cuando hay una clara separación entre los mayas de la región oriental, levantados en armas, y los de la occidental, que aceptan las nuevas condiciones de peonaje, además de combatir a los rebeldes. Aquellos que fueron hechos prisioneros, fueron enviados a Cuba, en un comercio prácticamente esclavista. El autor realiza una descripción de la situación de vida y trabajo de estos mayas. Excelente análisis de la intervención de gobiernos extranjeros (Inglaterra, E.U.A., España y Cuba) en ayuda de los criollos yucatecos contra los mayas rebeldes. de Castas y el henequén, México, El Colegio de México, $1970,392 \mathrm{p}$.

Obra básica, muy completa, sobre la guerra de Castas, con innumerables datos y un análisis profundo de los mismos, haciendo énfasis en la industria henequenera, lo que significó para Yucatán y su desarrollo en este siglo. El autor intenta "relacionar dos grandes temas de la historia social (raza y tierra), dentro de un amplio marco en el que confluyen la historia política, la económica y la diplomática. En este último punto se buscan principalmente las conexiones con Cuba y con España, con Estados Unidos y con Inglaterra". Contiene dos apéndices: estadístico y documental, además de una amplia bibliografía. 


\begin{abstract}
BCWDC E51 .A48 COLMEX 970.1 Jones, Grant D., "La estructura política de los mayas de Chan Santa Cruz: el papel del respaldo inglès", América Indigena, vol. 31, núm. 2, 1971, México, p. A512 415-428.

El autor discute las relaciones económicas y políticas de los mayas de Chan Santa Cruz con los ingleses, sugiriendo que la supervivencia de los jefes cruzob y de su sistema político dependió en gran parte del apoyo económico y político que recibieron de los ingleses del norte de Belice y también del apoyo de la British Colonial Office. De esta forma la fuerza politica de los mayas rebeldes se derivó sólo en parte de su propia y continua inspiración. Este enfoque ayuda a explicar por qué la sociedad de Chan Santa Cruz y su cultura fueron capaces de sobrevivir en un relativo aislamiento social por tanto tiempo y contra todas las probabilidades. Bibliografía.
\end{abstract}

BCWDC

G-N1

Jones, Grant D., "Revolution and Continuity in . A53 Santa Cruz Maya Society", American Ethnologist, vol. 1, núm. 4, 1974, p. 659-683.

Análisis del desarrollo que experimentó Chan Santa Cruz desde su creación, hasta finales del siglo XIX, especialmente en lo referente a su organización politicomilitar y religiosa. Se trata de un estudio comparativo entre esta comunidad del siglo pasado y su heredera en el Quintana Roo actual, Xcacal Guardia, donde prevalece el mismo sistema de organización sociopolitica, con base en las guardias, y el culto a la Cruz. El autor considera a Xcacal no meramente como una "rareza", producto de la guerra de Castas, sino como un ejemplo significativo de una adaptación reciente del sistema político maya tradicional.

BCWDC
F1435 F1435

Y9A57

COLMEX

972.011

J77a

mas diversos. La idea para la realización de esta antología partió del Encuentro Anual de la Asociación Antropológica Americana, en Toronto, en 1972, donde los participantes se interesaron en el uso de las fuentes históricas y metodológicas diversas al estudiar el cambio sociocultural en la península de Yucatán. La primera parte consiste en tres estudios sobre el cambio y la continuidad en las fronteras de los mayas de la península como grupo étnico. La segunda parte incluye cuatro artículos sobre los procesos de adaptación en la sociedad maya. La tercera y última parte se refiere a la visión maya de la historia, con tres artículos sobre la guerra de Castas. Los más importantes son: a) Dumond, D.E., "Independent Maya of the Late Nineteenth Century: Chiefdoms and Power Politics", p. 103-138; b) Bricker, Victoria R., "The Caste War of Yucatan: the History of a Myth and the Myth of History", p. 251258; c) Burns, Allan F., "The Caste War in the 1970's: Present-day accounts of Village Quintana Roo", p. 259-274. Bibliografia general muy extensa. 
COLMEX CE 972.011 L315m

Lapointe, Marie, Los Mayas Rebeldes de Yucatán, Zamora, El Colegio de Michoacán, 1983, 258 p.

Se trata de un estudio sobre la guerra de Castas en el que la autora analiza su desarrollo hasta 1901, sus bases sociales y económicas, y explica las implicaciones externas de un conflicto en el que intervienen el gobierno federal, la oligarquía yucateca y el imperialismo británico, interesado en la resistencia de los cruzob. La obra es una síntesis novedosa en cuanto a que aporta una suma de documentos procedentes de los archivos de Belice, Londres, Mérida y México. Extensa bibliografía.

BCWDC Menéndez, Carlos R., Historia del infame y vergonF1376 M533

BNAL 972.64056 MENE. $h$. zoso comercio de indios vendidos a los esclavistas de Cuba por los politicos yucatecos desde 1848 hasta 1861, Mérida, La Revista de Yucatán, 1923, 408 p.

Según Howard Cline, lo más valioso de esta obra es el tratamiento que el autor da al comercio de los esclavos mayas hechos prisioneros durante la guerra de Castas. Sin embargo, en cuanto a la guerra en sí, su tratamiento es más bien débil, al intentar demostrar que los mayas rebeldes tenían un claro interés en la actividad política, lo que los llevó a seguir el ejemplo de los politicos blancos y a levantarse en armas en una especie de golpe de Estado. Importantes documentos de la época en los anexos.

$\begin{array}{ll}\text { BCWDC } & \text { BNAL } \\ \text { F1376 } & 972.64 \\ . \text { M564 } & \text { MENE.h. } \\ \text { v. } 1 & \\ \text { BCWDC } & \\ \text { F1376 } & \\ \text {.M5342 } & \\ \text { v. } 2 & \end{array}$

Menéndez, Carlos R., Hombres y sucesos de otros tiempos (Cuadernos de Historia), Mérida, Compañia Tipográfica Yucateca, vol. 1, 1938-1940, vol. 2; 1943-1948.

Esta obra, compuesta de numerosos panfletos, reedita en su mayor parte fuentes primarias para la historia de Yucatán. Enumeramos algunas: "La pavorosa situación de Yucatán en 1849", sobre las acusaciones del gobierno de Barbachano de que los ingleses dotaban de armas a los mayas rebeldes para continuar con la sublevación; "Grave violación de la soberanía de México en Isla Mujeres en 1862-63"; "El proyecto expansionista de Inglaterra en Yucatán en 1849"; "La isla de Cozumel, república de negros norteamericanos en el Caribe"; "Itinerario de Grijalva en 1518"; y obras de Joaquín Hübbe, Waldeck, E. Rogers, Cepeda Peraza, Francisco Cantón Rosado, Daniel G. Brinton, etcétera.

COLMEX 972.64 P4118p

\section{$1980,317 \mathrm{p}$}

Peniche Vallado, Leopoldo, Promotores e historiadores de la rebelión maya de 1847 en Yucatán (Constancia crítica), Mérida, Fondo Editorial de Yucatán,

En palabras del autor, esta obra pretende "escuetamente formular un estudio crítico de los historiadores que la hicieron y de la actuación de los políticos -incluidos en esta denominación gobernadores, consejeros y jefes militares- en cuya época acaeció el acontecimiento (la guerra de Castas), y que asumieron responsabilidades en el curso que éste siguió". En la primera parte de la obra, el autor hace un estudio de las motivaciones económicas, políticas y psicosociales de la guerra de Castas. En la segunda parte incluye 
su análisis de textos de Carlos R. Menéndez, Ramón Berzunza Pinto, Fidelio Quintal Martín, Antonio Canto López, Oswaldo Baqueiro Anduze, Héctor Pérez Martinez y Howard Cline, entre otros.

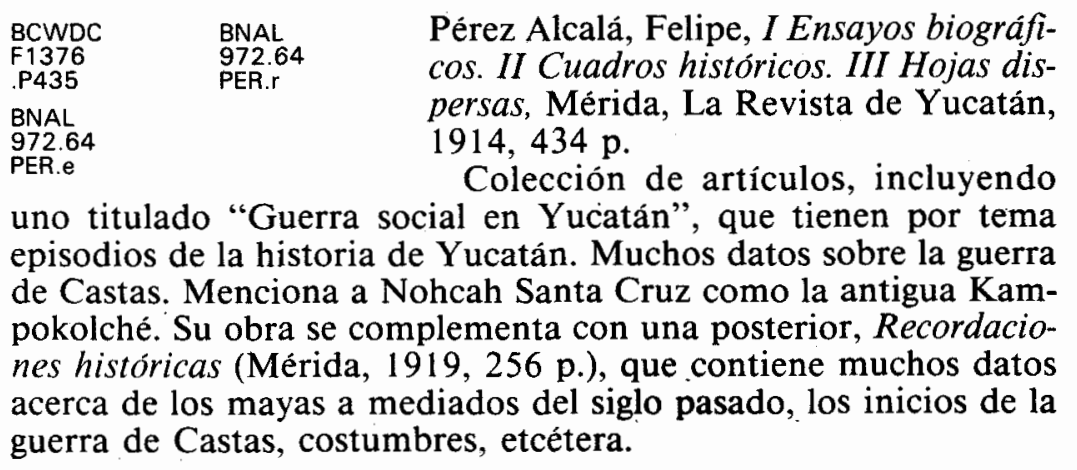

BCwDC Pérez Martínez, Héctor, "Orígenes económicos y soF 1376

$\$ 64$ ciales de la guerra de Castas", Diario de nuestro viaje

BNAL

972.6405

SIE. d. a Estados Unidos, de Justo Sierra O'Reilly, México, Antigua Librería Robredo, 1938, p. ix-li.

Importante estudio sobre la situación económica y social de Yucatán al inicio de la guerra de Castas y causas que la desencadenaron. Basada en fuentes secundarias, esta obra fue escrita como prólogo al diario de Justo Sierra O'Reilly y hace hincapié en la situación de las luchas políticas en Yucatán como una de las principales causas del estallido de la guerra de Castas. Bibliografía.

BCwDC Pérez Galaz, Juan de Dios, "La iniciación de la gueF1435 rra de Castas", Yikal Maya Than, p. 123, 139, 140, 149 y 150 , año 2, vol. 2, núm. 23, julio, 1941. Mérida, Oriente.

Breve pero analítico estudio de la situación económica y política que imperaba en Yucatán al iniciarse la guerra de Castas, haciendo énfasis en el papel de los mayas en las luchas partidistas y en la explotación económica de que eran objeto, causas ambas fundamentales del levantamiento armado. Reimpresión en Lorena Careaga, comp., Lecturas básicas para la historia de Quintana Roo, Chetumal, Fondo de Fomento Editorial, 1980, vol. 4.

BNAL Reed, Nelson, La guerra de Castas de Yucatán, Mé972.640556 . xico, ERA, 1976, 297 p.

REE.g
1976

Hasta la fecha, uno de los estudios más importantes, completos y amenos sobre la guerra de Castas, desde sus antecedentes, hasta la situación de los cruzob en 1959. Reed, que no es historiador profesional, se basó en la bibliografía comentada de Howard Cline sobre el levantamiento maya de 1847 y produjo un clásico. Según The American Historical Review, el autor de esta obra "no sólo ha escrito una bella relación de la guerra de Castas; también nos ha ofrecido el primer análisis penetrante de los sistemas social y económico de Yucatán en los siglos XIX y XX". Extensa bibliografía, cronología de la guerra de Castas y glosario de términos mayas. Prólogo de Howard F. Cline. 


\begin{abstract}
BCWDC Rogers, E., Honduras Británicas: sus recursos y desaG76 rrollo. Los indios de Santa Cruz, Yucatán, Mérida, BNAL Compañía Tipográfica Yucateca, 1938, $34 \mathrm{p}$.

908 Discurso pronunciado en el Ateneo de Manchester MIS.81 el 14 de octubre de 1885 publicado luego como panfleto de propaganda que pretendia atraer colonos a Honduras Británica. Numerosos e interesantes datos sobre los mayas rebeldes de Chan Santa Cruz. Fue traducido por primera vez al castellano por Manuel Cantón Ramos y publicado por Carlos R. Menéndez en su serie Cuadernos.
\end{abstract}

$\begin{array}{ll}\text { BNAL } & \text { COLMEX } \\ 972.005 & 972.005 \\ \text { ARCH.b } & \text { M611b }\end{array}$

BNAL

972.005

BOL.d.

Sierra O'Reilly, Manuel Antonio, “La guerra de Castas en Yucatán y el señor Pbro. don Manuel Sierra O'Reilly", Boletín del Archivo General de la Nación, ría de Gobernación, p. 235-254. vol. 21, núm. 2, 1950, México, Secreta-

Manuel Antonio Sierra O'Reilly, hermano de Justo Sierra O'Reilly, era vicario en Valladolid al inicio de la guerra de Castas. Fue elegido representante de la ciudadania para intentar formalizar un tratado de paz con los mayas rebeldes, en enero de 1848 . En marzo de ese año, la plaza de Valladolid cayó en manos de los rebeldes y el vicario fue hecho prisionero. Logrando escapar, se trasladó a su curato en el pueblo de Bolonchenticul. Formó parte de una comisión de sacerdotes representantes del gobierno yucateco, dirigida por el padre José Canuto Vela, para intentar nuevamente la pacificación de los mayas. Los documentos reproducidos en este artículo corresponden a esta etapa de su vida.

$\begin{array}{ll}\text { BCWDC } & \text { BNAL } \\ \text { F } 1376 & \text { R } \\ .593 & 0.82 .1 \\ \text { BGMCP } & \text { MIS. } 177 \\ 972 & \text { COLMEX } \\ \text { Su } & \mathbf{3 2 0 . 9 7 2 6 4} \\ & \text { S9399i }\end{array}$

Suárez y Navarro, Juan, Informe sobre las causas y carácter de los frecuentes cambios políticos ocurridos en el estado de Yucatán y medios que el gobierno de la Unión debe emplear para la unión del territorio yucateco..., México, Ignacio

Cumplido, $1861,189 \mathrm{p}$.

Obra en que se hace un tratamiento extenso del comercio de esclavos mayas rebeldes entre Yucatán y Cuba, así como otros temas referentes a la guerra de Castas, que van más allá de los indicados en el título de la obra. Cubre información importante sobre la situación de Yucatán entre 1850 y 1860 particularmente en lo que se refiere a las luchas partidistas. El autor fue enviado especialmente para hacer una investigación sobre estos temas por el presidente Juárez y éste es el informe que presentó a su regreso de la península.

BCWDC Thompson, Edward H., "A Page of American HisE1 72 tory", Proceedings of the American Antiquarian Society, vol. 17, octubre, 1905, Filadelfia, p. 239-252.

Artículo histórico muy interesante sobre la actuación de un batallón de soldados americanos enviados a subyugar a los mayas rebeldes de Chan Santa Cruz. Descripción de una guerra de guerrillas, en la que todos los recursos de la población local cuentan en la derrota de un ejército moderno y poderosamente armado. Ejemplos de "guerra biológica" utilizada por los mayas de Chan 
Santa Cruz para defender su ciudad sagrada. Howard Cline califica este artículo de relato muy útil, casi único, de lo que eran las batallas de la guerra de Castas.

HNAL

Valle, Rafael Heliodoro, "La destrucción de Bacalar", Revista de Revistas, año 24, núm. 1286, enero 6,

1935, México, 3 p., s.n.

El autor de este interesante artículo conoció en Belice a don José María Rosado, descendiente de Angel Remigio Rosado, uno de los siete supervivientes de la matanza que realizaran los cruzob en Bacalar en 1848. El autor encontró también en Belice la reseña que publicó el periódico beliceño Clarion sobre lo sucedido en Bacalar entre 1848 y 1858 , y reproduce numerosos pasajes de tal reseña. Ver "The indian uprising in Bacalar, as told in a letter (1915) to Bishop Murphy, S. J." en Belice, junio 25, 1931, Clarion, p. 1. en el Archivo Genaro Estrada de la Secretaria de Relaciones Exteriores, L-E-803 R, leg. 1.

\section{Belice}

\begin{tabular}{|c|c|c|}
\hline & 567 & ", Bole \\
\hline \multicolumn{3}{|r|}{$\begin{array}{l}\text { e de Bac } \\
\text { uientes d } \\
\text { s inglese }\end{array}$} \\
\hline
\end{tabular}

BNAL Baranda, Joaquín, La Cuestión de Belice, Campeche, 082.1

MIS. 103 Sociedad Tipográfica, 1873, $126 \mathrm{p}$.

Como gobernador de Campeche, Baranda emitió este informe en 1873, dando cuenta al gobierno federal de la situación de Belice durante la guerra de Castas, las actividades de los mayas rebeldes de Chan Santa Cruz, de Marcos Canul, jefe de los sublevados pacíficos de Icaiché y su relación con los colonos beliceños. Datos sobre el tráfico de armas, conflictos de límites, etc. Incluye importantes documentos al respecto en el apéndice.

BCWDC Calderón Quijano, José Antonio, Belize (1663-1821):

${ }_{C}{ }_{17}^{1446}$ historia de los establecimientos británicos del rio VaBNAL lis, hasta la Independencia de Hispanoamérica, Sevi972.82 lla, Escuela de Estudios Hispanoamericanos de la CAL. b. Universidad de Sevilla, Publicación 5, 1944, 503 p.

Amplio estudio que contiene información sobre la Gobernación de Yucatán, el descubrimiento de la costa oriental de Yucatán, el origen de Belice, la batalla de Bacalar en 1733, la explotación del palo de tinte por los ingleses en Yucatán, etc. Contiene, además, varios apéndices con documentos importantes y mapas. 
BCWDC F 1449 .B4C3

COLMEX 972.82 $0349 i$

Castellanos, Francisco Xavier, La Intendencia de Yucatán y Belice, México, s.e., 1962, 62 p.

Contiene información sobre la intendencia de $\mathrm{Yu}$ catán y Belice, el obispado de Yucatán, el territorio que hoy ocupa Belice, el origen de esta colonia y un análisis jurídico del conflicto fronterizo con Belice y Guatemala. Destaca un mapa de Yucatán y los territorios adyacentes de los "Itzaex o Indios Mayas, los Tipuanos, Quicheaches, Mopanes, Lacandones, Choles, etc., con el distrito de Vera Paz... mostrando también la ruta probable de Cortés en su marcha de México a Honduras, por Dudley Costello, Esq., Londres, John Murray, 1854".

BCWDC

$\mathrm{F} 1446$

3

.64

1967

BNAL

972.8204

CLE. $b$.

Clegern, Wayne M., British Honduras: Colonial Dead End. 1859-1900, Baton Rouge, Louisiana State University Press, 1967, 214 p.

Estudio basado en la tesis doctoral del autor (The International Role of British Honduras, 1859-1900, Berkeley, University of California, 1959). Abarca la historia de Belice desde fines del siglo pasado y se centra en los aspectos de la transformación del asentamiento de cortadores de palo de tinte en la colonia de Honduras Británica, sus problemas fronterizos con México, el auge y caída de la producción forestal y la búsqueda de nuevos caminos en su desarrollo económico. Contiene mucha información sobre la frontera entre México y Belice: tratados, comercio ilegal de armas, la guerra de Castas, el jefe Marcos Canul de Icaiché, los mayas de Chan Santa Cruz, etcétera.

$\begin{array}{ll}\text { BCWDC } & \text { COLMEX } \\ \text { F 1449 } & 972.82 \\ \text {.B7F3 } & F 114 b\end{array}$

BNAL

972.82

FAB. $b$
Fabela, Isidro, Belice: Defensa de los derechos de México, México, Mundo Libre, $1944,423 \mathrm{p}$.

Obra muy completa sobre el problema de Belice. Contiene datos y documentos sobre los derechos de España sobre Belice; Belice como parte de la Capitanía General de Yucatán; posteriores derechos de México y relaciones con Inglaterra al respecto, etc. En los anexos se presentan documentos relativos a la definición de limites, como los tratados con Inglaterra, los informes del secretario de Relaciones Exteriores, y otros. Contiene un mapa de los ríos Valiz, Nuevo y Hondo. Fotos, ilustraciones, bibliografía.

BCWDC Gibbs, Archibald R., British Honduras: a historical F1446 . $\mathrm{G} 44$

BNAL

972.82

GIB. $b$.

and descriptive account of the colony from its settlement, 1670, Londres, Sampsonhow, Marston, Searle and Rivington, $1883,198 \mathrm{p}$.

Adecuado resumen de la historia y la economia de Belice. Aporta datos interesantes sobre las mismas. Son de especial interés los capitulos referentes a la guerra de Castas y a los indios de Chan Santa Cruz y de Icaiché, sus relaciones con los colonos beliceños, el comercio de armas, etc. Asimismo, menciona las expediciones efectuadas por varios oficiales británicos a Chan Santa Cruz, para entablar diversas negociaciones con los cruzob o servir de intermediarios en las negociaciones de paz con Yucatán (Blake, Fancourt, Plumridge, Twigge, etc.). Detalla las relaciones 
de Belice con los sublevados "pacíficos" de Chichanhá y el ataque de Icaiché y San Pedro al poblado de Orange Walk.

\begin{abstract}
BCWDC Hübbe, Joaquín, Belice, Mérida, Compañía Tipográ1446

.18

BNAL

972.64

HUB. $b$.

fica Yucateca, 1940, $164 \mathrm{p}$.

Esta obra, escrita por un alemán naturalizado ciudadano yucateco, apareció originalmente en forma diario yucateco El Eco del Comercio, dirigido por D. Manuel Heredia Argüelles. El autor tomó mucha información del informe publicado por el secretario colonial de Belice, Henry Fowler, en 1879 , haciendo un análisis profundo y adecuado de dichos datos, y complementándolos con otras obras de la época. Su interés es el de dar a conocer la geografía, economía, organización política e historia de la colonia británica, a fín de que Yucatán pueda defenderse de los posibles afanes expansionistas de Inglaterra y del creciente apoyo que los colonos beliceños daban a los mayas rebeldes. La obra contiene gran cantidad de información y detalles circunstanciales sobre los cacicazgos mayas independientes, Chan Santa Cruz, etcétera.
\end{abstract}

BCwDC Humphreys, Robert A., The Diplomatic History of
F1449
B7H8
COLMEX
Colish Honduras, 1638-1901, Londres, Oxford Uni-
972.8203 .
H $927 \mathrm{~d}$ Además de la historia de Belice como asenta-
conflictivas entre Inglaterra y España al respecto, se habla aqui de
las demandas de Guatemala sobre esta región, y se incluye abun-
dante información sobre conflictos fronterizos con Yucatán, trata-
dos de límites, indios sublevados de Chan Santa Cruz y su rela-
ción con los colonos beliceños, los "sublevados pacificos" y sus
incursiones en tierra beliceña, etc. Bibliografía.

BNAL Lafragua, José Ma. e Ignacio Vallarta, Corresponden972.08842 cia diplomática cambiada entre el gobierno de la ReMEX.c. pública y el de Su Majestad Británica con relación al territorio llamado Belice, 1872-1878, México, Ignacio Cumplido, $1878,94 \mathrm{p}$.

Además de los documentos que constituyen la correspondencia, y que arrojan luz sobre los arreglos diplomáticos a los que querian llegar México e Inglaterra, habla esta obra del ataque de los indios de Icaiché al poblado de Orange Walk en septiembre de 1872, dirigidos por Marcos Canul. Esta obra es de gran interés por reunir los puntos de vista de ambos lados del conflicto fronterizo.

Destaca especialmente la carta enviada por Vallarta a Lord Derby el 23 de marzo de 1878 , la cual se considera un ejemplo de aplicación de la diplomacia, a la vez que defiende los derechos de México sobre Belice y acusa a Gran Bretaña de prolongar la guerra de Castas al permitir que los colonos beliceños vendan armas a los mayas rebeldes.

Macías Zapata, Gabriel Aarón, "Transformaciones histórico-regionales de la frontera México-Belice", en La formación histórica de la frontera sur. Andrés Fábregas, ed., México, CIESAS, 1985, p. 199-304. 
Análisis de los cambios históricos y políticos por los que ha pasado la región del río Hondo, es decir, la frontera entre Belice y Quintana Roo. Se inicia con una descripción de la situación geográfica y cultural de la región en la época prehispánica, durante la Conquista y la colonización españolas, resaltando tres aspectos de la Colonia: la encomienda, el contrabando y la pirateria. El autor lleva a cabo un estudio de los conflictos entre España e Inglaterra frente a los cortadores de palo de tinte, y el subsecuente aumento de dichos conflictos en la etapa independiente y durante la guerra de Castas, en que los colonos ingleses proveían de armas a los mayas rebeldes. Finaliza con el Porfiriato, la Revolución y la posrevolución, cuando se inicia el reparto de tierras y la reforma agraria del río Hondo.

BNAL

327.72097282

Mariscal, Ignacio Informe del C. Ignacio Mariscal, MEX. i secretario del Despacho de Relaciones Exteriores rendido ante el Senado, acerca del Tratado de Limites entre Yucatán y Belice, México, F. Diaz de León, 1893, 55 p.

La definición de límites entre Belice y Yucatán (y el subsecuente tratado) suscitó una ola de protestas, especialmente entre los yucatecos, ya que consideraban que México, como nación, tenía plenos derechos sobre Honduras Británica. Sin embargo, por decisión de Porfirio Diaz, se terminaron los conflictos que a propósito de esta frontera habia con Inglaterra y, en 1893, el tratado fue firmado. Ignacio Mariscal, como secretario de Relaciones Exteriores, tuvo que explicar y justificar este acto político, para poner fin a la controversia suscitada al respecto. En el informe realiza un recuento histórico desde la fundación de Belice a principios del siglo XVII, intentando demostrar que dicho territorio nunca perteneció a la Capitania de Yucatán, más que, tal vez, la zona norte, de ahí la imposibilidad de México de reclamarla para sí. El otro argumento importante era la necesidad de suprimir el tráfico de armas entre colonos beliceños y mayas rebeldes, por medio de un control riguroso de la línea fronteriza, y de ahí la firma del tratado. Incluye interesantes datos sobre los mayas de Chan Santa Cruz y los sublevados pacíficos, varios apéndices, entre ellos el texto del tratado y citas de Manuel Orozco y Berra, tomadas de su Memoria histórica sobre Belice.

Paz Salinas, M. E., Belice, el despertar de una nación, P 3487b México, Siglo XXI, 1983, 192 p.

Esta obra analiza la realidad contemporánea de Belice, especialmente en lo que toca a su autodeterminación y soberanía, las cuales apoya y justifica. Dentro de su temática se habla de Belice y su integración al marco del capitalismo dependiente, la génesis de la nacionalidad beliceña, su configuración estructural, el proyecto de desarrollo, Belice en la encrucijada internacional, su lucha por la independencia en el marco de la descolonización y el caso de Belice en los foros internacionales. Cuenta con una extensa bibliografía y un apéndice de fuentes primarias. 
BCWDC Peniche, Manuel, Historia de las relaciones de EsF1446

.P41 paña y México con Inglaterra sobre el establecimiento

BNAL

972.82

PEN.h.

de Belice, Mérida, Compañía Tipográfica Yucateca, 1940,67 p.

En el subtítulo se aclara que es "una copia del que dirigió al gobierno del príncipe Maximiliano el enviado extraordinario de Inglaterra, Mr. Campbell Scarlet, adjunto a su comunicación de 6 de marzo de 1866". Contiene un buen mapa de Belice y datos importantes sobre el papel desempeñado por Honduras Británica en la guerra de Castas, especialmente lo referente al tráfico de armas entre colonos beliceños y mayas rebeldes.

$\begin{array}{lll}\text { BCWCD } & \text { COLMEX } & \text { Pérez Trejo, Gustavo A., Documentos } \\ \text { F1449 } & 972.64 & \text { sobre Belice o Balice, México, Impre- } \\ \text { B4P4 } & \text { C3522 } & \text { sora de Estampillas y Valores, 1958, } \\ \text { BNAL } & & 209 \text { p. } \\ 972.82 & & \end{array}$

Estudio sobre el origen de Belice y los conflictos que al respecto se suscitaron entre Inglaterra, España y México. Análisis de los documentos más importantes que se refieren a la participación de Belice en la guerra de Castas, las relaciones entre los mayas rebeldes y los colonos beliceños, los tratados fronterizos, etc. Contiene bibliografía, asi como un artículo anónimo titulado "Belice: estudio sobre el origen de ese nombre (1877)", que analiza los cambios fonéticos y ortográficos del nombre del pirata inglés Wallace, quien fundara la colonia pasando por Wallis, Wallix, Valiz, Balis, Balize, Bellize, hasta llegar a Belice.

COLmeX Prats y Beltrán, Alardo, Visión actual de Belice, Mé972.82 P112v xico, LibroMex, 1958, 194 p.

Interesante y muy completo recuento de lo que ha sido Belice en este siglo, su desarrollo, su lucha por la independencia y los problemas contemporáneos con México y Guatemala, posteriores a la firma de los tratados de límites. Incluye una breve reseña histórica de la creación de Belice, para luego entrar de lleno en la problemática actual de su soberania, el petróleo, la política, etc. Cuenta con apéndices sobre el tratado de límites con México $\mathrm{y}$ con fotos.

BCWDC
F1449
B7M33
BNAL
R
327.72097283
MEX. $\mathrm{t}$

Secretaría de Relaciones Exteriores, Tratado de limites entre los Estados Unidos Mexicanos y Honduras Británicas, seguido de los principales documentos que a él se refieren (Edición Oficial), México, La Europea, $1897,130 \mathrm{p}$.

En esta obra, además del texto del tratado Mariscal-Spencer firmado en 1893, se encuentra un mapa de los límites del río Hondo y el texto de dicho tratado en inglés. También se incluye el dictamen de la comisión de la Secretaría de Relaciones Exteriores y otros documentos al respecto. 


\section{Historia de Quintana Roo, desde su creación en 1902 hasta que se convierte en estado libre y soberano en 1974.}

BNAL 917.265 AGU. i

Aguirre, Amado, Informe que rinde al $C$. Presidente de la República el Jefe de la Comisión nombrada por él mismo, para hacer el estudio del Territorio Federal de Quintana Roo..., Tacubaya, Dirección de Estudios Geográficos y Climatológicos, 1925, 56 p.

El general e ingeniero Amado Aguirre fue gobernador de Quintana Roo en 1924 y realizó, por órdenes de Plutarco Elías Calles, un estudio sobre la situación económica, política y administrativa del territorio. El Informe consta de una síntesis histórica, un estudio de su población (en especial de los mayas), una descripción geográfica de sus litorales, lagunas y el río Hondo, medios de comunicación, riqueza forestal, comercio de los productos forestales, caza, pesca, condiciones económicas y, finalmente, conclusiones y proposiciones para sacar al territorio de Quintana Roo de su aislamiento y desarrollarlo convenientemente.

COLMEX Aguirre, Amado, Mis memorias de campaña; apuntes 972.09

A284 $\mathrm{m}$ para la historia, México, s.e., 1953, $430 \mathrm{p}$.

En diciembre de 1924, el Gral. Amado Aguirre fue nombrado por Plutarco Elías Calles jefe de una comisión para realizar un estudio político, administrativo y económico del territorio de Quintana Roo, con el propósito de establecer si debía ser devuelto a Yucatán, o dividido entre Yucatán y Campeche, o bien conservado para la Federación. En el capítulo 38 (p. 344-355) de sus Memorias, el Gral. Aguirre relata su actuación como gobernador de Quintana Roo y en especial su acción en contra del movimiento delahuertista encabezado por el mayor Atanasio Rojas cuyo diario cita directamente.

BNAL

972.65

ALV. $h$.

COLMEX

972.6

A473 $h$.

Alvarez Coral, Juan, Historia de Quintana Roo, Chetumal, Gobierno de Quintana Roo, 1971, 239 p.

Hasta fines de la década de los setenta, esta era la única obra sobre la historia de Quintana Roo que podia ser fácilmente consultada y que presentaba un panorama bastante completo, aunque un tanto superficial, de los hechos históricos que han caracterizado a la región. Se inicia en 1840 , con los antecedentes inmediatos de la guerra de Castas, y termina con la resolución del conflicto de límites entre Quintana Roo, Campeche y Yucatán en 1940. Contiene un capítulo con las biografias de los gobernadores del territorio hasta 1974 y una importante sección de apéndices.

BNAL

972.65

AlV.h.

COLMEX

972.65

A437 in

Alvarez Coral, Juan, Historia de Quintana Roo a partir de la guerra de Castas, México, Gobierno de Quintana Roo, 1972, 169 p.

Tesis de licenciatura en historia del autor. En la temática que aborda incluye los siguientes temas: Breve explicación de la guerra de Castas, Bacalar y la fundación de Chan Santa Cruz, tratado de límites con Inglaterra y campaña de pacificación de los rebeldes, fundación de Payo Obispo, creación de Quintana Roo y primer gabinete gubernamental, gobernadores de Quintana Roo de 1935 a 1971, geografía humana y eco- 
nómica, conflictos de límites con Campeche y Yucatán, biografías de Andrés Quintana Roo y de los gobernadores del territorio, conclusiones, bibliografía, apéndices, mapas y tabla cronológica de gobernantes.

BNAL

923.09726

ALV.g

Alvarez Coral, Juan, Galería de gobernadores de Quintana Roo, Chetumal, Gobierno de Quintana Roo, 1975, 212 p.

Colección de breves biografías de los gobernadores que ha tenido Quintana Roo desde que fuera creado como territorio federal en 1902, hasta 1974, en que se convirtiera en estado libre y soberano y eligiera a su primer gobernador constitucional. La lista está incompleta e incluye información general y un tanto superficial, sin realizar un análisis profundo de la actual política de cada uno de los gobernadores. Incluye una biografía de Andrés Quintana Roo y, en los apéndices, documentos referentes a los nombramientos de los gobernadores y el texto del decreto que convierte al territorio de Quintana Roo en estado, el 8 de octubre de 1974.

IOC

Avila Zapata, Felipe Neri, El general May, último jefe de las tribus mayas, Mérida, Gobierno del Estado de Yucatán, 1974, $150 \mathrm{p}$.

Interesante obra que resulta básica para entender una etapa central de la historia de Quintana Roo, como fue la del dominio del general Francisco May sobre la zona de Felipe Carrillo Puerto y su monopolio de la producción chiclera, la cual controló desde fines de la guerra de Castas (1901), hasta que alcanzó su auge, en 1929. El autor relata sus experiencias como secretario del Gral. May y es, además, una guía del archivo, que conservó después de la decadencia del dominio de May y ordenó cronológicamente. Entre los documentos de dicho archivo, hoy propiedad del gobierno del estado de Quintana Roo, se encuentran cartas, telegramas, contratos, nombramientos, denuncias, etc. Proporcionan un panorama muy completo del manejo de la producción chiclera y de la vida de los chicleros.

BNAL Bautista Pérez, Francisco, Chetumal (I), Chetumal,

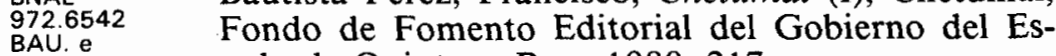
tado de Quintana Roo, 1980, 217 p.

Primer volumen de una colección de tres (los tomos II y III no se han publicado aún), que da una visión bastante completa de la historia de la ciudad de Chetumal, desde la época prehispánica, hasta 1940, pasando por una descripción de los cacicazgos mayas de Uaymil y Chactemal, la conquista y colonización de la región, la guerra de Castas, la fundación de Payo Obispo y los años subsecuentes, hasta que tomó el nombre de Chetumal, actual capital del estado de Quintana Roo. Cuenta con importantes documentos y muchas fotografias tomadas del archivo de Manuel J. Palma.

Bcwoc Canto López, Antonio, El Territorio de Quintana rritorio y consideraciones acerca de su reincorporación a Yucatấn), Mérida, H. Congreso del Estado de Yucatán, 1954, 92 p.

Son siete artículos publicados en el Diario del Sureste de Mé- 
rida, en julio de 1954. Se trata de un estudio de los distintos aspectos que entrañan la problemática de la reincorporación de Quintana Roo a Yucatán. Se inicia con los primeros rumores, en 1896, de la creación de un territorio federal a partir de la región oriental de Yucatán y la actuación del entonces gobernador de Yucatán, Francisco G. Cantón. Analiza los aspectos económico y político de las subsecuentes desapariciones y recreaciones de Quintana Roo en 1915 y en 1931. Menciona datos sobre Quintana Roo tomados del Anuario Estadistico de los Estados Unidos Mexicanos, 1951-1952, México, 1954. para la historia de Quintana Roo, Chetumal, Fondo Quintana Roo, 1980, 6 vols. de Fomento Editorial del Gobierno del Estado de

El objeto de esta colección es el de proporcionar una serie de textos originales, de época, asi como fuentes secundarias de autores de reconocido prestigio, que complemente el estudio básico de la historia de Quintana Roo y sirva de guía para una investigación histórica más profunda. La colección comprende un total de seis volúmenes que llevan los siguientes títulos: vol. 1: Panorama prehispánico, vol. 2: Descubrimiento y Conquista, vol. 3: La Colonia, vol. 4: La Guerra de Castas, vol. 5: Las Relaciones con Belice, vol. 6: La Creación del Territorio de Quintana Roo y su desarrollo hasta 1974 .

BIM

972.004

92

CAR.ch
Careaga Viliesid, Lorena, Chan Santa Cruz: historia de una comunidad cimarrona de Quintana Roo, (tesis de Licenciatura), México, Universidad Iberoameri-

Obra que consta de tres partes, en la primera de las cuales se hace un análisis de la teoría del campesinado reconstituido del Caribe y de sus orígenes en los movimientos cimarrones que tuvieron lugar en todo el continente americano, como respuesta a las plantaciones con mano de obra de esclavos. En la segunda parte, se aplica esta teoría al origen y desarrollo de Chan Santa Cruz, comunidad fundada por los mayas rebeldes durante la guerra de Castas. En su tercera y última parte se presenta el desarrollo histórico de Chan Santa Cruz, que es la actual población de Felipe Carrillo Puerto, Quintana Roo.

BIM Careaga Viliesid, Lorena, Quintana Roo: entre la 372.897 267 CAR.q selva y el mar, monografía estatal, México, SEP, 1982. $284 \mathrm{p}$.

Monografía realizada como experimento, dentro del proyecto de monografías estatales de la Secretaría de Educación Pública. Contiene información sobre la geografía, la historia y la situación actual de Quintana Roo, para alumnos de $4^{\circ}, 5^{\circ}$ y $6^{\circ}$ grados de primaria. El índice es el siguiente: El Mundo Natural, El Mundo Prehispánico, Descubrimiento y Conquista, La Colonia, La Guerra de Castas, El Territorio de Quintana Roo hasta 1930, Los Años de Transformación, 1930-1974, Vida actual en Quintana Roo. 
BIM

330.972

CES.e

César Dachary, Alfredo y Stella M. Arnaiz Burne, Estudios socioeconómicos preliminares de Quintana Roo, Puerto Morelos, CIQRO, 1983-1986, 4 vols.

El conjunto de estos cuatro volúmenes es el primer estudio socioeconómico que se hace sobre el estado de Quintana Roo. Cubre los últimos 80 años y abarca la dinámica poblacional y todos los sectores de la economía. El primer volumen, "El territorio y la población", da una visión de la ocupación de la costa oriental de la península desde 1902 hasta la creación del estado, migraciones, divisiones territoriales, etc. El segundo volumen se titula "Sector agropecuario y forestal" y analiza las etapas del desarrollo agropecuario y forestal y la organización y especialización de los municipios en los últimos treinta años. El tercero, "Sector turismo", analiza el desarrollo de las diferentes áreas turísticas en el estado, visitantes, infraestructura y derrama económica. El cuarto y último volumen se títula "Sector comunicación y transportes, comercio, industria, servicios y finanzas" y analiza el desarrollo de estas actividades en el estado y sus tendencias en los últimos años.

BCCC Covián Martinez, Vidal Efrén, El almirante Don B del A Othón P. Blanco, victorense ilustre, Ciudad Victoria, Gobierno del Estado de Tamaulipas, 1978, 28 p.

Biografia del fundador de Payo Obispo, hoy Ciudad Chetumal, el 22 de enero de 1898 . Se describe su infancia, juventud, carrera en la armada y su labor en la fundación de Payo Obispo, la construcción del Pontón Chetumal, que se situó en la desembocadura del río Hondo, el recorrido del pontón, el comercio ilegal de armas entre los colonos beliceños y los mayas rebeldes, el levantamiento de un poblado de tres hectáreas de extensión y la labor de atracción de yucatecos que, por temor a los indios rebeldes, se habían ido a vivir a la colonia inglesa. Payo Obispo cambió su nombre al de Chetumal el 28 de septiembre de 1936, siendo desde 1916 la capital de Quintana Roo. Actualmente es también cabecera municipal del municipio de Othón P. Blanco. El autor es el cronista de Ciudad Victoria, Tamaulipas.

BCwDC Gómez Alonso, Paula, "El Territorio de Quintana Boletín de la Sociedad Mexicana de Geografia y Estadistica, vol. 47, núms. 3, 4 y 5, agosto, 1938, México, p. 289-312.

910.6272

SOC. $b$

El tema de este artículo es el de las vicisitudes sufridas por Quintana Roo como entidad política. En opinión de la autora, el gobierno federal no habia realizado a la fecha esfuerzo real ni efectivo por sacar al territorio del aislamiento, despoblamiento y olvido en el que se encontraba desde la época de la Conquista y Colonia españolas. Describe la situación de Bacalar a merced de la pirateria inglesa; la guerra de Castas y las expediciones armadas para tratar de someter a los mayas rebeldes; los límites entre México y Honduras Británica; la creación del territorio de Quintana Roo, la protesta de Yucatán y el gobierno brutal del Gral. Bravo durante el Porfiriato, y las subsecuentes desmembraciones de Quintana Roo. Ter- 
mina con las acciones del Comité Pro-Territorio de Quintana Roo, que, en diciembre de 1934, logró su creación definitiva.

BNAL

GON.2

González Durán, Jorge, La zona maya (Los rebeldes de Chan Santa Cruz), Mérida, Impremers, 1978, $97 \mathrm{p}$.

Este autor quintanarroense lleva a cabo una investigación y análisis de la guerra de Castas y de la fundación y desarrollo de Chan Santa Cruz, hoy Felipe Carrillo Puerto, Quintana Roo, para "buscar la verdad histórica con el objetivo de encontrar enseñanzas, valor e impulso para luchar con mejores armas por las transformaciones revolucionarias que reclama la sociedad de nuestro tiempo". Es de interés primordial explicar el complejo proceso histórico que propició la formación de la zona maya de Quintana Roo, y difundirlo entre la población de la región. Bibliografía

BNAL HOY.b

Hoy, Carlos, Breve historia de Quintana Roo, México, Gobierno del Territorio de Quintana Roo, 1971, 92 p. (2a. ed., 1973).

Algunos fragmentos de esta obra fueron publicados en el semanario El Quintanarroense, órgano informativo de la Sociedad de Estudiantes Quintanarroenses en Yucatán, en 1967, y en El Informador de Quintana Roo, en los años 1968-1969. El autor se propone reunir algunos apuntes históricos sobre el territorio de Quintana Roo, para ser de utilidad a los estudiantes de escuelas superiores, a profesionales y a aquellos que realicen investigaciones y trabajos de tesis sobre Quintana Roo. Temática: Descripción geográfica. Conquista y Colonia. Guerra de Castas. Límites con Belice y conflictos fronterizos. Creación del territorio de Quintana Roo y fundación de Payo Obispo. Biografias de Othón P. Blanco y de Andrés Quintana Roo. COLMEX Hoy, Carlos, "Estado de Quintana Roo y ciudad de

972.003

E56 Chetumal", Enciclopedia de México, sobretiro especial, Chetumal, 1977, 48 p.

Se trata de una separata de los artículos "Quintana Roo" y "Chetumal", publicados en la Enciclopedia de México. Incluye los cinco documentos fundamentales que rigieron la erección del territorio de Quintana Roo en estado libre y soberano, con las semblanzas personales de los diputados al Congreso Constituyente y a la I Legislatura, y el texto integro de la Constitución Política del Estado.

$10 \mathrm{C}$

Lavalle Argudín, Mario, Biografia del vicealmirante C. G. Othón P. Blanco Núñez de Cáceres y fundación de Payo Obispo, México, Secretaría de Marina, Asociación de la Heroica Escuela Naval, A. C., 1976, 29 p.

Como su título indica, en esta biografía del fundador de Payo Obispo -hoy Chetumal- se reseña su vida y se hace hincapié en la etapa que corresponde a la fundación de este poblado, cuando Othón P. Blanco era aún subteniente. El texto está tomado del diario personal del propio Blanco, reproduciéndose integramente el capitulo de la historia de Quintana Roo. Reproduce también de varios otros documentos interesantes de personajes de la época. Termina la biografía con la bienvenida que se dio a Blanco en 
Payo Obispo, durante su visita en noviembre de 1927, 29 años después de haberla fundado.

$\begin{array}{ll}\text { BCwDC } & \text { Menéndez, Gabriel Antonio, Quintana Roo: álbum } \\ \text { Fl333 } & \text { monográfico, México, s.e., 1936, 226 p. } \\ \text {.05 } & \text { Obra clásica de la historia de Quintana Roo. Con- } \\ \text { BNAL } & \text { siste en una serie de artículos periodísticos sobre su } \\ 917.265 & \text { historia desde 1902, su economia, en especial la pro- } \\ \text { MEN. m. } & \text { ducción chiclera, las comunidades mayas, el desarrollo de sus } \\ \text { duccion } & \text { principales poblaciones, la visita del Gral. Lázaro Cárdenas como } \\ \text { candidato a la presidencia, y una serie de diversos aspectos de la } \\ \text { realidad quintanarroense en 1936. El Fondo de Fomento Editorial } \\ \text { del Gobierno del Estado de Quintana Roo publicó en 1979 una } \\ \text { edición facsimilar, en la que el Album Monográfico se reprodujo } \\ \text { tal como fue publicado originalmente, en tintas sepia y verde. }\end{array}$

BCWDC Rebolledo, Miguel, Quintana Roo y Belice, México, Fi333 Stylo, 1946, 106 p.

BNAL

917.26

REB.q

El autor fue vicecónsul en Belice y secretario del brigadier de la armada Angel Ortiz Monasterio en 1901 , época en que este último dirigió la parte marítima de la ofensiva final contra los mayas rebeldes. Tal estudio histórico sobre Quintana Roo fue escrito en 1936 y tomado básicamente de las memorias y documentos personales del autor. Asimismo, toma datos de los historiadores yucatecos Ancona y Baqueiro y de los informes -sobre Belice de la Secretaría de Relaciones Exteriores y documentos anexos al tratado de límites. La obra esta dividida en cuatro partes: 1) Breve descripción geográfica del territorio y relación sucinta de la guerra de Castas hasta la pérdida de Bacalar. 2) Consideraciones sobre la colonia de Honduras Británica hasta el acuerdo con Inglaterra sobre los límites. 3) Establecimiento del primer consulado mexicano en Belice. Expedición militar, ocupación y creación, del territorio de Quintana Roo. 4) Cambios producidos por la Revolución en el territorio. Situación actual y porvenir. Contiene también apéndices sobre Quintana Roo en 1936 y la cuestión de Belice en 1946.

BCWDC Rosado Iturralde, Gonzalo de Jesús, Breve historia de F1333

.R6 Cozumel, Chetumal, Gobierno del Territorio de

BNAL

972.65

ROSA. b. Quintana Roo, 1949, 210 p.

La obra consiste en una historia de la isla de Cozumel, que hace especial hincapié en el descubrimiento de la isla por los españoles, la presencia en ella de Cortés y Pánfilo de Narváez, los episodios de Gonzalo Guerrero y Jerónimo de Aguilar, y la conquista por Francisco de Montejo. Incluye capítulos sobre los filibusteros en Cozumel y varios episodios históricos del siglo pasado. Apéndices y bibliografia. El interés de esta obra radica en que es uno de los pocos estudios históricos que existen sobre la isla de Cozumel, y precisamente subraya esa gran laguna en la historia de Quintana Roo que es Cozumel e Isla Mujeres, a pesar de haber estado habitadas desde la época prehispánica y no haber pasado directamente por el conflicto social de la guerra de Castas, ni haber tenido serios obstáculos y retrocesos en su desarrollo socioeconómico. 
INAH

LBS

F1333

R788 p

Rosado Vega, Luis, Un pueblo y un hombre, México, A. Mijares y Hno., 1940, $445 \mathrm{p}$.

Libro escrito sobre la base de las experiencias del autor en sus distintos viajes al territorio de Quintana Roo, especialmente en 1937, como miembro de la Expedición Científica Mexicana, y el homenaje al pueblo quintanarroense y a su gobernador, el Gral. Rafael E. Melgar. El relato incluye varios capítulos de contenido histórico: época prehispánica, descubrimiento, conquista y colonia, rebeliones indígenas, la guerra de Castas, las relaciones con Belice y la firma del tratado de límites, el fin de la guerra de Castas y la creación del territorio de Quintana Roo. El autor realiza un análisis del territorio en cuanto a su demografia y economía haciendo especial hincapié en las obras que realizó el gobierno de Melgar: abastecimiento de agua, vías de comunicación, el cooperativismo, etcétera.

IOC

Vallarta, Luz del Carmen, "La formación histórica de Payo Obispo Chetumal, 1898-1940", Identidad, año 3 , núm. 5, número especial 1986-1987, Chetumal, p. 30-34.

Este artículo tiene como propósito hacer una reconstrucción histórica del proceso de formación y desarrollo de la ciudad capital del estado de Quintana Roo, desde que fue fundada en 1898 con el nombre de Payo Obispo, hasta 1940, ya llamada Chetumal, siendo el cardenismo un punto culminante de su historia. La autora se basa en una extensa recopilación de documentos de archivo y hace hincapié en la gran importancia que los poblados fronterizos de Belice tuvieron en los inicios de la colonización y desarrollo de Payo Obispo.

INAH
AS32
C280p
No. 559
BCWDC
AS32.
A5
No. 559
BCWDC
F1333
.V5

Villa Rojas, Alfonso, The Maya of East Central Quintana Roo, Washington, Carnegie Institution of Washington, Publicación 559, 1945, $182 \mathrm{p}$.

Hasta la fecha, esta obra es uno de los estudios más importantes sobre los mayas de Quintana Roo. El autor, a pesar del aislamiento en que se encontraban los mayas y de su rechazo hacia cualquier extranjero, especialmente hacia los mexicanos, logró penetrar en las comunidades sagradas de Tixcacal Guardia, Chunpom, Señor y Chancah, haciéndose pasar por un vendedor ambulante, que recorría las selvas de Quintana Roo a lomo de mula. Este clásico de la historia y la etnografía de Quintana Roo no fue traducido al castellano sino hasta 1978, y publicado por el Instituto Nacional Indigenista con el título de LoS Elegidos de Dios. Dentro de los apéndices incluye el texto de los rezos mayas para la ceremonia del Okotbatam, los textos de los sermones de la Cruz Parlante, traducidos de los manuscritos encontrados en Chan Santa Cruz, y la bibliografia comentada de Howard Cline sobre la guerra de Castas, desde 1847 hasta 1910. 


\section{Obras generales sobre diferentes aspectos de Quintana Roo} BNAL Bassols Batalla, Angel, et al., Estudio geográfico y socio-económico del estado de Quintana Roo, México, 910.6272 SOC.b INAH G5 M6

5684 Sociedad Mexicana de Geografía y Estadistica, 1976, 288 p. (Boletín de la SMGE, tomo CXXIV, 1976)

Libro que trata de una investigación interdisciplinaria "sobre terreno y gabinete, con duración de 16 meses, para tratar de cooperar en la labor de conocer los recursos naturales, la problemática social y económica, así como algunos aspectos históricos y metodológicos del nuevo estado". Contiene mapas y una bibliografía básica geográfica y económica de Quintana Roo y Belice; índice e introducción general; estudio de Quintana Roo; recursos naturales; algunos aspectos socioeconómicos de la población; diagnóstico económico del estado de Quintana Roo y estrategia para su desarrollo. Cuenta con una bibliografía básica.

BNAL Brito Sansores, William, Toponimia maya de Quin479.48103 BRI. $\mathrm{t}$ tana Roo, Chetumal, Fondo de Fomento Editorial del Gobierno del Estado de Quintana Roo, 1981, $122 \mathrm{p}$.

Diccionario de nombres de lugares en maya -especialmente pueblos- de Quintana Roo. Incluye datos importantes sobre el origen de esos nombres, muchas veces ligados a las caracteristicas geográficas del lugar.

BNAL Escobar Nava, Armando, Geografía general del es$\begin{array}{ll}917.265 & \text { tado de Quintana Roo, Chetumal, Fondo de Fo- } \\ \text { ESC. } 9 . & \end{array}$ mento Editorial del Gobierno del Estado de Quintana Roo, $1981,140 \mathrm{p}$.

Dividida en dos partes: geografía física y geografía humana, esta obra presenta un panorama amplio de la geografía de Quintana Roo, incluyendo datos sobre su localización, límites, clima, geologia, hidrologia, flora y fauna, división política, población, actividades económicas, servicios, etc. Incluye bibliografía, fotos y un mapa de Quintana Roo de la SAHOP, 1978.

BCwDC Herrera, Horacio, Monografia del rio Hondo, QuinF1333 .144 tana Roo, México, Instituto Panamericano de Geografia e Historia, $1942,160 \mathrm{p}$.

Durante la administración de Adolfo de la Huerta,

BCWDC

F1401

P153

No. 82

COLMEX

917.26

H565 m

el autor fue miembro de una expedición organizada por la Secretaría de Hacienda, al frente de la cual estaba el Ing. Pedro C. Sánchez, quien ya habia encabezado la Comisión Geográfico-Exploradora de Quintana Roo en 1918. En esas fechas había quedado pendiente el levantamiento del río Hondo, tarea encomendada al autor. Describe las dificultades a las que se enfrentó la expedición en una tierra inhóspita y aislada, así como su estancia en Payo Obispo en enero de 1920 y su visita a Belice. Abarca los siguientes temas: límites internacionales, datos geográficos generales, cuencas o sistemas fluviales, geologia, hidrometría, clima, historia, geografía humana, flora y fauna, geografía económica. Contiene bibliografía 
y una interesante colección de 14 mapas sobre el río Hondo y su afluente, el río Azul.

COLMEX

330.97265

ir68.p

BNAL

330.97265

MEX. p.
Irigoyen, Ulises, et al., El problema económico de Quintana Roo, México, Secretaría de Hacienda y Crédito Público, 1934, 461 p.

En la época en la que el autor, a la cabeza de la Comisión Federal Investigadora, llegó a Quintana Roo -enero de 1934- el territorio no existía como tal, sino que había sido dividido entre Yucatán y Campeche. La Comisión estaba formada por representantes de las secretarías de Hacienda, Comunicaciones y Obras Públicas, Economía Nacional, Educación Pública, Agricultura y Fomento, y el Departamento de Salubridad Pública. El autor inicia su informe con un estudio sobre el problema económico y la repoblación del exterritorio, y luego describe los pormenores de su visita a Cozumel, los mayas de Santa Cruz, la ciudad de Payo Obispo, cuestiones educativas, problemas aduanales, Belice y varios temas más. Incluye un capítulo sobre las condiciones económicas en Chiapas y el intercambio comercial entre México y los países de Centroamérica. El tercer capítulo es en sí el informe de la Comisión y las medidas necesarias que ésta recomienda para poblar, desarrollar y vincular a Quintana Roo con el centro del país. Finalmente incluye un estudio geográfico del territorio de Quintana Roo por el Gral. José Siurob, exgobernador, realizado en 1925.

BCwDC Jiménez, Luis G., El chicle, su explotación forestal e SB291

. . 555 industrial, México, Ediciones GTo, 1951, 125 p.

El tema central de la obra es la producción de chicle en la península de Yucatán y especialmente en Quintana Roo. El autor proporciona datos geográficos, caracteristicas del árbol del chicle (chico zapote, Achras zapota), su explotación y preparación, aspectos económicos e industriales, la vida del chiclero en las selvas de Quintana Roo y un análisis comparativo con la producción en otras entidades. Cuadros y gráficas interesantes.

BCWDC Lundell, Cyrus L., "Chicle exploitation in the sapoQ1 123 dilla forest of the Yucatan Peninsula", Field and Laboratory Journal, vol. 2, núm. 1, noviembre, 1933, p. No. 1 $15-21$.

Artículo basado en la información recopilada por el autor durante cuatro temporadas de estudio y exploración en la península de Yucatán entre 1928-1929, época del gran auge chiclero en Quintana Roo y Belice. Contiene un estudio del árbol del chicle, Achras zapota, de sus variedades y características. Realiza también un análisis de su importancia comercial y de la manera en que la resina o látex se extrae y procesa. Finaliza con un breve comentario acerca de la destrucción de los bosques, la imposibilidad de cultivar los árboles y la necesidad de dejarlos descansar durante cierto periodo para asegurar la producción.

Quintana Roo; procesos políticos y democracia, México, CIESAS, 1986, 103 p. (Cuadernos de la Casa Chata, 132)

Colección de artículos sobre política y democracia en el estado 
de Quintana Roo: "El derecho público: legislación y prácticas en Quintana Roo", de Ma. Cristina Castro Sariñana; "Política y relaciones interétnicas en la zona maya de Quintana Roo: el caso del municipio de Felipe Carrillo Puerto", de Luz del Carmen Vallarta; "La penetración protestante en la zona maya de Quintana Roo", de Antonio Higuera Bonfil; "La reforma política y el sistema unipartidista en Quintana Roo", de Gabriel Macias Zapata; y "Las perspectivas del sistema político y la democracia en Quintana Roo", de Ma. Cristina Castro Sariñana. Cada artículo incluye bibliografía. El CIESAS ha publicado otros cuadernos que incluyen trabajos sobre Quintana Roo, como El cambio social en el sureste de México (1985) y Antropologia de las Artesanias en el sureste de México (1985).

BCwDC Pacheco Cruz, Santiago, Geografia del territorio de F1333 Quintana Roo, México, Sociedad Mexicana del Geografia y Estadistica, $1958,310 \mathrm{p}$.

Libro premiado en el Concurso Nacional organi917.265 PAC. $\mathbf{g}$. zado por la Secretaría de Educación Pública y El $\mathrm{Na}$ cional. Contiene información sobre la geografía de Quintana Roo, escrita para escolares, agrupada en geografía física, política y económica. En esta última parte hace una interesante descripción de la vida en Quintana Roo hacia 1950, incluyendo a las comunidades indigenas, los festejos de las Bodas de Oro de la fundación de Chetumal y los estragos causados por el famoso ciclón "Janet", que azotó las costas de Quintana Roo en 1955.

BCWDC Redfield, Robert, "Los mayas actuales de la peninF1376 sula yucatanense", Enciclopedia Yucatanense, Méxi.E55 BIM. 972.65 ENC. Y co, Edición Oficial del Gobierno del Estado de Yucatán, 1946, vol. 6, p. 7-30.

Artículo que aporta datos recabados durante varios meses de trabajo de campo realizado por el autor cuando se encontraba en Chan-Kom, donde elaboró su obra clásica acerca del continuum folk urbano. Contiene mucha información sobre el territorio de Quintana Roo, en especial sobre las comunidades de la zona maya, y está seguido de "Los mayas del actual territorio de Quintana Roo" de Alfonso Villa Rojas.

BNAL

Sánchez, Pedro C. y Salvador Toscano, Informe renBCWDC HC 137 $.05 A 5$ 1918 dido por la Comisión Geográfico-Exploradora de Quintana Roo al C. Secretario de Fomento, México, Oficina Impresora de la Secretaría de Hacienda, Departamento de Fomento, 1918, 57 p.

La Comisión Geográfico-Exploradora de Quintana Roo salió de México a fínes de noviembre de 1916 y llegó a Cozumel, Quintana Roo, en el cañonero "Zaragoza" unos días después. Realizó el primer estudio profundo y completo de la geografía del territorio, de sus recursos naturales, de la flora y fauna y de las condiciones sanitarias. Incluye, además, una descripción de los pormenores de la expedición. 
COLMEX

330.97265

Ir68p

BNAL

330.97265

MEX. $p$

Siurob, José, "Estudio geográfico del territorio de Quintana Roo", El problema económico de Quintana Roo, de Ulises Irigoyen, México, SHCP, 1934, p. $387-461$.

Descripción de la geografía física y económica del territorio, incluyendo límites, suelos, hidrografía (lagunas, bahías, etc.), islas, vías de comunicación, clima, geología, fauna, flora, pesca, recursos forestales, producción silvícola (maderas preciosas y chicle), cooperativas, concesiones de selva productiva, condiciones sanitarias, agricultura y ganadería, población, colonización, los mayas, ruinas arqueológicas, etc. El autor, general de brigada y médico, fue gobernador de Quintana Roo en 1927.

BIM Sodi Morales, Demetrio, “Textos de Quintana Roo”, M868 La Literatura de los Mayas, México, Joaquín Mortiz, LIT. $\mathrm{m} \quad 1976$, p. 57-68.

Primera publicación en castellano de textos en inglés y maya que fueron reproducidos originalmente en las obras de Villa Rojas (The Maya of East Central Quintana Roo, 1945) y de Redfield (Chan Kom: A Maya Village, 1962). Los textos se refieren a rezos cantados durante las ceremonias de la siembra del maíz y otras. Versión de Demetrio Sodi.

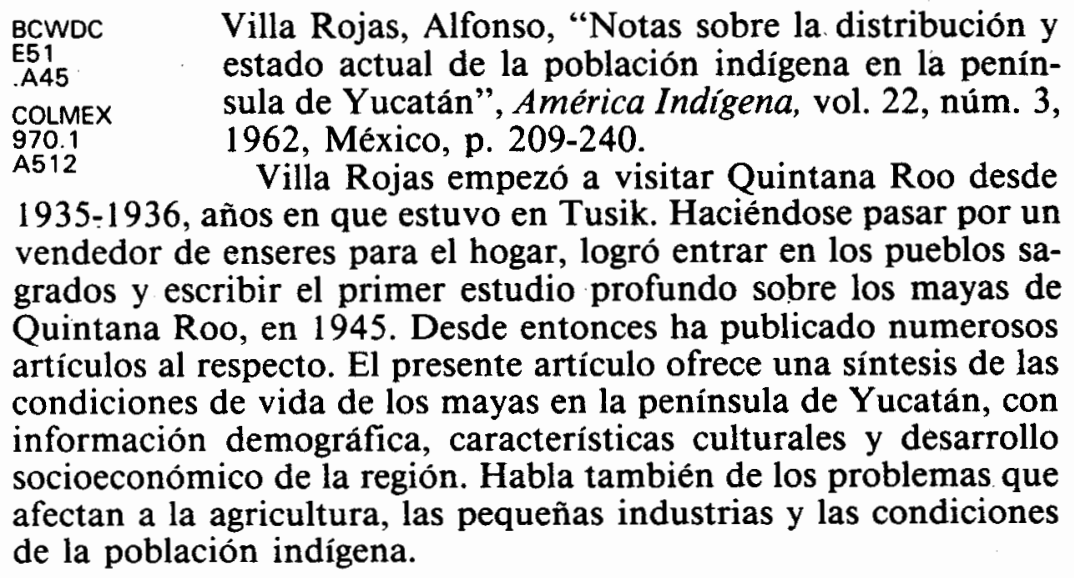

\section{Crónicas y diarios de viajeros y exploradores nacionales y extran- jeros.}

\begin{tabular}{|c|c|}
\hline $\begin{array}{l}\text { BCWDC } \\
\text { F1201 } \\
.567\end{array}$ & $\begin{array}{l}\text { Aldherre, Fred y M. Mendiolea, "Los Indios de Yu- } \\
\text { catán", Boletin de la Sociedad de Geografia y Esta- }\end{array}$ \\
\hline $\begin{array}{l}\text { BNAL } \\
\text { B } \\
910.6272 \\
\text { SOC. b. }\end{array}$ & $\begin{array}{l}\text { distica de la Republica Mexicana, } 2 \text { a. época, vol. } 1 \text {, } \\
\text { 1869, p. } 73-81 \text {. } \\
\text { El autor era oficial austriaco, miembro del grupo }\end{array}$ \\
\hline $\begin{array}{l}\text { INAH } \\
\text { G5 } \\
\text { M6 } \\
\text { S684 } \\
\text { primera }\end{array}$ & $\begin{array}{l}\text { militar del emperador Maximiliano, que visitó Chan } \\
\text { Santa Cruz, la ciudad sagrada de los mayas rebeldes, } \\
\text { en } 1865 \text {. Su informe es una descripción extensa y de } \\
\text { se de la organización física e institucional de Chan }\end{array}$ \\
\hline Santa & ste informe, escrito \\
\hline
\end{tabular}


BCWDC F14444 . $\mathrm{C} 664$

BNAL

917.265

COO. $n$.

Cook, James, Notas sobre una travesia desde el rio Balise, en la bahia de Honduras, hasta Mérida, capital de la provincia de Yucatán, en las Indias Occidentales Españolas, Mérida, Compañia Tipográfica Yucateca, 1936, $14 \mathrm{p}$.

Recuento del viaje que realizó este explorador inglés en 1765 desde Belice, por el río Hondo y varios de sus canales, hasta el poblado de Bacalar. Describe la navegación en esta primera parte del viaje, el panorama, la vegetación y la fauna típicas del manglar quintanarroense. Habla de Bacalar, del fuerte de San Felipe y del poblado de Chunhuhub, haciendo un recuento de los problemas a los que se enfrentó para conseguir provisiones. Excelente descripción de la selva tropical en todos sus aspectos y de la vida colonial en los pueblos y en la ciudad de Mérida, costumbres, construcciones, gobierno, vivienda, vestido, cultivos, etcétera.

BCWDC Dame, Lawrence, Yucatán, Nueva York, Random F1376

.D25

BNAL

917.264

DAM. $y$.

House, 1941, $374 \mathrm{p}$.

Este libro es el relato de las experiencias de viaje del autor en el estado de Yucatán, incluyendo una larga visita al territorio de Quintana Roo. En forma bastante amena y detallada, cuenta su recorrido por los poblados de Tihosuco, Santa Cruz, Vigía Chico y Cozumel, entre otros, así como su encuentro con los mayas rebeldes, refugiados en las selvas de Quintana Roo.

Bcwoc Fowler, Henry, A narrative of a journey across an F1444 F78 unexplored portion of British Honduras with a short sketch of the history and resources of the colony, Belice, The Government Press, 1879, 86 p.

Esta obra es uno de los informes más importantes de los viajeros que visitaron el oriente de Yucatán entre 1870 y 1880 , ya que da una idea muy clara de lo que eran Chan Santa Cruz y los mayas rebeldes en esos años, con datos de primera mano y observaciones directas. Contiene mucha información sobre el río Hondo, el dominio de los rebeldes sobre Bacalar, el tráfico ilegal de armas, etc. Hace también un análisis profundo de la economía, organización política, geografía e historia de Belice, haciendo especial hincapié en sus recursos, la explotación forestal, la posibilidad de atraer a un mayor número de colonos y los conflictos fronterizos entre México y la Gran Bretaña. Fowler fue secretario colonial durante esos años.

1972

Gann, Thomas W.F., Ancient Cities and Modern Tribes: exploration and adventure in Maya lands, Nueva York, B. Blom, 1972, 256 p.

Descripción arqueológica, etnológica e histórica de los lugares que visitó el autor durante una de sus exploraciones en la peninsula de Yucatán, en 1926, incluyendo el actual Quintana Roo. Son especialmente interesantes los datos que proporciona sobre Payo Obispo, hoy Chetumal, las ruinas cercanas de Ichpaatun, Tulum, Cobá e Isla Mujeres. 
BCwDC Gann, Thomas W. F., "The Maya Indians of SouE51

U6

No. 64

BCWDC

F1435

G19 thern Yucatan and Northern British Honduras", Bulletin of American Ethnology, núm. 64, 1918, Washington, Smithsonian Institution, $146 \mathrm{p}$.

Estudio arqueológico y etnológico que incluye datos interesantes sobre las comunidades mayas rebeldes de Chan Santa Cruz, Icaiché y Chichanhá, y de sus pobladores, durante la guerra de Castas. Hasta la aparición de la obra de Villa Rojas sobre los mayas de Quintana Roo en 1945, la obra de Gann habia sido la única fuente confiable de información acerca de los cacicazgos mayas independientes en el siglo XX. Mucha información está tomada de los informes de William Miller (1887) y de Carl Sapper (1895).

INAH Larsen, Helga, "Trip from Chichen-Itza to Xcacal,

Quintana Roo", Ethnos, vol. 29, 1964, México, p. 5-42.

La autora fue secretaria del reconocido arqueólogo Sylvanus G. Morley, entre 1935 y 1936. En aquella época, Morley se encontraba dirigiendo las excavaciones en Chichen-Itzá, bajo los auspicios de la Carnegie Institution de Washington. Los eventos que describe este artículo ocurrieron entre el 26 de febrero y el. 8 de marzo de 1936, y está tomado directamente del diario personal de la Sra. Larsen. El recorrido incluyó los poblados quintanarroenses de Tihosuco, T'lal, Tiná, Chandzonot, San José y Tusik, hasta llegar a Xcacal, uno de los tres pueblos sagrados mayas, herederos de la tradición politicorreligiosa de Chan Santa Cruz. Describe su estancia en dicho poblado, la organización de las guardias y sus impresiones del jefe maya Yum Cituk. Excelentes fotos, algunas de ellas de colección.

COLMEX Lizama Escoffie, Homero, En las riberas del Caribe: 917.266 L7892e BCWDC $4 \mathrm{~F}$
MEX.54 bosquejo histórico-geográfico del territorio federal de Quintana Roo, 1920-1923, Mérida, Oriente, 1927, 240 p.

Recuento de un viaje de navegación alrededor de las costas de la península de Yucatán, especialmente desde Cabo Catoche a la bahía de Chetumal y por el río Hondo. El autor describe con lujo de detalles técnicos en qué consiste esa navegación y habla también de la situación política de Quintana Roo en 1923, además de incluir numerosas anécdotas de personajes locales, situaciones, lugares, etcétera.

BCWDC Machlin, Milt y Bob Marx, "First visit to three AP2 forbidden cities", Argosy, 1971, vol. 372, núm. 5, p. 18-28.

Descripción de la entrada de los autores en las ciudades sagradas de los mayas de Quintana Roo: Chancah, Xcacal y Chunpom, en busca de un códice maya. Dicho códice, según leyendas, sería la "Piedra Roseta" de América que permitiria descifrar los jeroglífícos mayas. El códice, desde luego, no existe, pero el artículo es interesante en cuanto a las descripciones de los pueblos y sus iglesias y a la permanencia de los rituales politicorreligiosos y de la ideologia heredada de la guerra de Castas. 
BCWDC

F1435

.1

. $63 \mathrm{M} 3$

BNAL

913.7264

MAL. i.
Maler, Teobert, Impresiones de viaje a las ruinas de Cobá y Chichen-Itzá, Mérida, J.E. Rosado E., 1932, $74 \mathrm{p}$.

Recuento de un viaje al oriente de la península de Yucatán llevado a cabo por el autor en septiembre de 1891. Descripción de la selva y de las brechas que la atravesaban para llegar a Cobá desde Chemax, y de los antiguos "sacbeob" o caminos de los mayas, siendo el principal el que une Cobá con la costa. Descripción de las ruinas de Cobá y de las lagunas adyacentes de Cobá y Macanxoc. Habla del peligro de encontrarse con mayas rebeldes habitantes de Tulum, lo que lo obliga a modificar sus planes y regresar a Chemax antes de lo planeado. Interesantes datos al respecto.

HNAL

Mendizábal, Miguel O. de, “Juan Bautista Vega, el secretario de Dios", El Universal, noviembre 21 , 1929, México, 1a. secc., p. 3 y 5.

El autor realizó un recorrido de un mes por el territorio de Quintana Roo junto con Ramón Beteta y varios periodistas, en 1929. El presente artículo surgió a raíz de su visita a Cozumel, donde conoció a Juan Bautista Vega, cacique de las tribus mayas de Muyil-Chunpom y nativo de Cozumel. Nacido en 1886, Juan Bautista Vega, vive una aventura increíble al ser hecho prisionero por los mayas rebeldes, en Chan Santa Cruz. El artículo cuenta esta extraordinaria aventura y la forma en que se convirtió en intérprete de la Cruz Parlante y cacique de una de las ciudades sagradas de los mayas.

BCWDC Miller, William, "A journey from British Honduras G7 to Santa Cruz, Yucatan (1888)", Proceedings of the Royal Geographical Society of London, vol. 11, núm. 1 , enero, 1889, Londres, p. 23-28.

Miller viajó a Honduras Británica con el título de inspector asistente general de la Colonia Británica en 1888. Llevaba asistentes y traductores en su visita a Chan Santa Cruz, pero su informe se refiere sobre todo a lo que observó. Este escrito es importante porque abarca una zona que no fue visitada por Carl Sapper en su viaje de 1894-1895 a los cacicazgos mayas independientes. Incluye un mapa de la región de Bacalar y Chan Santa Cruz, con la ruta que siguió desde Belice hasta este último poblado. Se complementa con otro titulado "Notes on a part of the western frontier of British Honduras", (Proceedings of the Royal Geographical Society of London, vol. 9, 1887, p. 420-423), que describe la geografia, fauna y flora de la colonia, así como a los mayas sublevados "pacíficos" de Icaiché y sus relaciones con los colonos beliceños.

BCWDC Ober, Frederick A., Travels in Mexico and Life F1215 .013

BNAL

917.2

OBE.t. among the Mexicans, Boston, Estes \& Lauriat, 1884, $672 \mathrm{p}$.

De los relatos de los viajeros que visitaron Yucatán entre 1880 y 1910 , el de Ober es uno de los que más información contiene. La primera parte habla de las regiones menos pobladas de la península, en especial del estado de Yucatán, y aporta datos sobre la vida social a fines del siglo pasado. 
Describe su visita a Cozumel, Isla Mujeres y Tulum y tiene un capitulo completo sobre la costa norte y noreste de Yucatán.

BNAL

917.265

PEI.m.

Peissel, Michel, El mundo perdido de los Mayas: exploraciones y aventuras en Quintana Roo, Barcelona, Juventud, 1976, $271 \mathrm{p}$.

Relato del viaje que el autor realizó por Quintana Roo en 1958. Describe su descubrimiento de la ciudad de Chunyaxché, la cual ha sido identificada como la antigua Muyil por otros arqueólogos. Aun cuando la parte arqueológica no sea del todo veraz o basada en un estudio profundo, y algunos nombres de lugares y datos históricos no estén correctos, su relato y las descripciones de la vida en Quintana Roo y en las comunidades mayas rebeldes son interesantes. En 1962 regresó a Quintana Roo para hacer un estudio más exhaustivo de las ruinas de Chunyaxché. Su recorrido por la costa, desde Palmul hasta San Pedro, Belice, es decir, prácticamente todo el litoral quintanarroense, es interesante y da una idea del aislamiento en que se encontraba, aún, en esa época. Buenos mapas y fotos.

$\begin{array}{lll}\text { BCWDC } & \text { P443y } & \text { Perigny, Maurice, "Yucatan Inconnu", } \\ \text { F1376 } & \text { COLMEX } & \begin{array}{l}\text { Journal de la Société des Américanistes } \\ \text { P44 }\end{array} \\ \text { LAL/TU } & 913.7005 & \text { de Paris, Paris, vol. 5, núm. 1, 1908, p. } \\ \text { L972.015 } & \text { S678 } & 1-20 \text {. } \\ (571) & & \text { El autor, conde francés, realizó un }\end{array}$
viaje desde Payo Obispo, a lo largo del río Hondo, hasta Icaiché. En este artículo da cuenta de sus observaciones y es de especial interés el mapa que incluye y los datos que proporciona sobre los mayas "sublevados pacíficos" de Icaiché, en la época en que se inicia la ofensiva y control finales de los rebeldes, y la desaparición de los cacicazgos independientes. Datos importantes sobre Payo Obispo en sus primeros años de vida.

BCWDC Sáenz, Moisés, México Integro, Lima, Torres AguiF1210 .$S 25$

BIM

086

SEP.0.25 rre, $1939,109 \mathrm{p}$.

El capítulo más importante de esta obra está descrito por el autor como "descripciones y relatos de un viaje que efectué en 1929, como miembro de una comisión oficial enviada para estudiar la situación social del Territorio de Quintana Roo... Reflexiones sobre nuestro Hinterland". Este capítulo incluye todos los artículos que aparecieron en los periódicos Excélsior y El Universal, en noviembre y diciembre de 1929, y que son los siguientes: "Desposeimiento", "Empleados, Indios, Chicleros y Comerciantes", "Nohoch Santa Cruz", "Chicle Caro: un hombre de Quintana Roo" y "El enigma de Quintana Roo". Estos articulos tratan del control que ejercia el Gral. May sobre la producción chiclera, lo que era Santa Cruz de Bravo, el comercio y el transporte, la agricultura, etc. Datos muy interesantes y de primera mano. 
La existencia de los cacicazgos mayas independientes fue primero dada a conocer de una forma extensiva por Carl Sapper, cuya descripción de los mismos sigue siendo una fuente en la que se han basado y se basan muchos estudios al respecto. Dicho relato va acompañado de un excelente mapa. Su evidencia de los cacicazgos de Icaiché e Ixkanhá está basada en observaciones de primera mano, pero su testimonio de Chan Santa Cruz se basa en otras fuentes, ya que Sapper nunca visitó esa zona.

BCWDC Stephens, John L., Incidents of Travel in Central America, Chiapas and Yucatan, Nueva York, Harper and Brothers, 1841, 2 vols.

Bim

917.28

El segundo volumen de esta obra está dedicado

STE.i parcialmente a Yucatán. Entre otras cosas, el viajero norteamericano proporciona una visión muy completa de la vida en las haciendas yucatecas y las condiciones sociales que imperaban en 1840 . Los dos volúmenes de su posterior trabajo: Incidents of Travel in Yucatan (Nueva York, Dover, 1963), publicado en 1843, están llenos de datos relevantes y de detalles meticulosamente observados y bien reportados.

Son interesantes sus descripciones de ruinas arqueológicas de la zona oriental, como Tulum. Además, da cuenta de los huites, o sea, los mayas habitantes de la costa oriental, considerados como salvajes por sus vestimentas y armas (arco y flecha).

Acompañó a Stephens en este viaje Frederick Catherwood, quien hizo dibujos detalladísimos, aún utilizados en la actualidad por los arqueólogos, de las ruinas mayas.

BCWDC Wright, Marie Robinson, Picturesque Mexico, PhilaF1215

.W85

folio delphia, Lipincott, 1897, 445 p.

Wright visitó en 1897 todos los estados y territo-

COLMEX

$\mathrm{CE}$

917.2

W952p rios federales de la República Mexicana, y publicó esta obra con interesantes fotos sobre el México porfirista. En el capítulo 43, que trata del estado de Yucatán, incluye descripciones de poblados de Quintana Roo, como Yalahau, Cozumel, Isla Mujeres, etc. Proporciona información sobre los mayas rebeldes de Chan Santa Cruz y las campañas en su contra en la época en que gobernaba el estado de Yucatán Carlos Peón.

\section{Bibliografias y guias de archivos.}

BEWA Andrews, E. Wyllis y Anthony P. Andrews, $A$ Preliminary Study of the Ruins of Xcaret, Quintana Roo, Nueva Orleáns, Tulane University, Middle American Research Institute, 1975, publicación 40, $117 \mathrm{p}$.

El autor, padre del coautor de esta obra, arqueólogo de reconocido prestigio, asociado a la Universidad de Tulane, en Nueva Orleáns se dedicó plenamente al estudio de las ruinas prehispánicas de Quintana Roo, en especial a las de la costa nororiental y a Cozumel. Aporta sobre Xcaret una bibliografia muy completa referente a la costa oriental de Quintana Roo, además de un indice total de los lugares con ruinas arqueológicas en la costa oriental. Habla de un proyecto de investigación en Cozumel para los años 1972-1973. Tiene también un índice de mapas sobre los mismos 
lugares, con una lista de fuentes, es decir, autógrafos, recopiladores, autores, editores e instituciones relativas a dichos mapas. Complementa la obra de Samuel K. Lothrop, "Bibliography of the East Coast of Yucatan", Tulum, an Archaelogical Study of the East Coast of Yucatan, Washington, Carnegie Institution of Washington, Publicación 335, 1924, p. 175-176.

$\begin{array}{lll}\text { BCWDC } & \text { COLMEX } & \text { Burdon, Sir John Adler, Archives of Bri- } \\ \text { F1441 } & 972.82 & \text { tish Honduras, Londres, Sifton Praed, } \\ . \text { A63 } & \text { B951a } & 1931-1935,3 \text { vols. }\end{array}$

En diversas ocasiones, los archivos de Belice se perdieron debido principalmente a los ciclones. De no ser por esta importante guía, se desconocerian numerosos documentos de la historia de Honduras Británica en el siglo pasado. El volumen III incluye gran cantidad de información sobre los cacicazgos mayas independientes, visitados por viajeros y oficiales del gobierno de Belice, correspondencia oficial sobre los conflictos de límites, etcétera.

$\begin{array}{ll}\text { BIM } & \text { Careaga Viliesid, Lorena, Bibliografia General de } \\ \text { B } & \text { Quintana Roo, Chetumal, Fondo de Fomento Edito- } \\ 016.972 & \text { rial del Gobierno del Estado de Quintana Roo, 1979, } \\ 67 & 186 \text { p. }\end{array}$

Recopilación bibliográfica que amplía, corrige y actualiza la primera bibliografía que se publicó sobre Quintana Roo y que realizaron Elena Gómez Ugarte y Aurora Pagaza en 1937. Las obras están ordenadas por autor, en orden alfabético. Contiene una sección de periódicos y revistas publicados en Quintana Roo, una sección de mapas y planos, y una sección de fuentes bibliográficas.

\begin{abstract}
INAH Cline, Howard F., "Remarks on a Selected BibliograA532 phy of the Caste War and Allied Topics", The Maya No. 559 of East Central Quintana Roo, de Alfonso Villa Rojas, Washington, Carnegie Institution of Washington, 1945, Publicación 559, apéndice C, p. 165-178.

Investigación bibliográfica comentada, básica para realizar cualquier estudio sobre la guerra de Castas de Yucatán y la creación del territorio de Quintana Roo. Amplios comentarios, orden cronológico, y organizada de la siguiente manera: obras de carácter general en español e inglés; colecciones generales de fuentes; antecedentes y relatos de viajeros, 1840-1847; antecedentes en artículos periodisticos de la época, 1840-1847; antecedentes y orígenes, asuntos eclesiásticos, 1840-1847; antecedentes y origenes, relaciones exteriores, 1840-1847; La Guerra de Castas, 1847-1853; La misión de Sierra, 1847-1848: La trata de esclavos, 1848-1863; Reajustes y tendencias principales, 1850-1865; Honduras Británica y Yucatán, 1848-1880; Yucatán, los mayas independientes y los cacicazgos, 1860-1880; Relatos de viajeros, 1865-1880; Cacicazgos 1890-1910; Relatos de viajeros, 1880-1910; El estado de Yucatán, 1880-1910 (henequén): materiales modernos; material bibliográfico y otras referencias.
\end{abstract}

$\begin{array}{ll}\text { BNAL } & \text { Garritz Ruiz, Amaya, Guia del Archivo Amado Agui- } \\ \text { B } & \text { rre. México, UNAM, Instituto de Investigaciones } \\ \text { G16.97209 } & \text { Históricas, 1982, 291 p. } \\ & \text { El Gral. Amado Aguirre realizó, en 1924, una ex- }\end{array}$ 
pedición a Quintana Roo para dar cuenta de la situación social y económica del territorio al entonces presidente de la República, Plutarco Elías Calles, quien lo nombró gobernador de Quintana Roo. Esta guía relaciona los documentos del archivo de este personaje, mismos que se encuentran en la biblioteca del Instituto de Investigaciones Históricas de la UNAM.

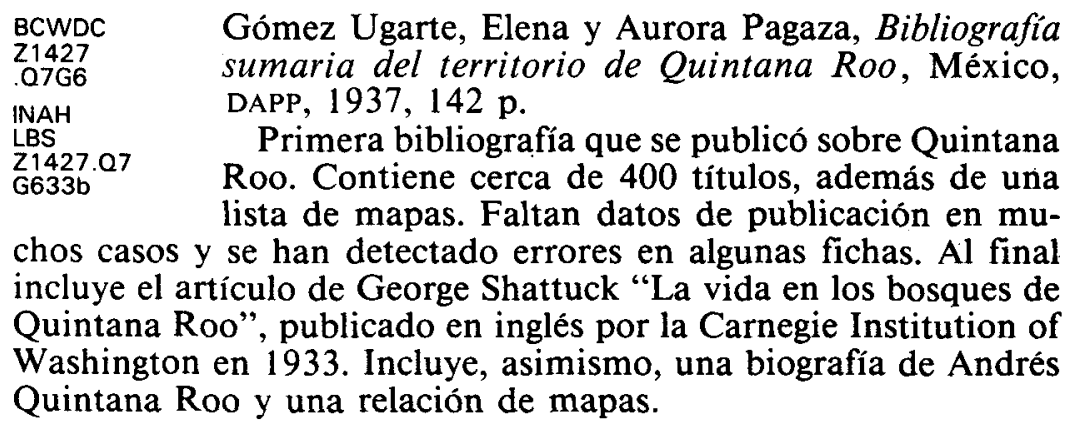

BCwoC Martínez Alomía, Gustavo, Historiadores de YucaM38 tán; apuntes biográficos y bibliográficos de los histoBNAL riadores de esta Peninsula desde su descubrimiento 016.97264 hasta fines del siglo XIX, Campeche, El Fénix, 1906, MAR.h. $\quad 360 \mathrm{p}$.

Colección de biografías, de las cuales las más interesantes son las que corresponden al siglo XIX. Entre éstas se encuentran la de Lorenzo de Zavala, Bartolomé Granados Baeza, Juan Pío Pérez, Estanislao Castillo, Gerónimo Castillo, John L. Stephens, Eligio Ancona, Crescencio Carrillo y Ancona, Joaquín Baranda, etc. Incluye también una bibliografía con recuentos de varios viajeros extranjeros y obras de estos historiadores yucatecos.

COLMEX Meyer, Jean, "México en los archivos diplomáticos y 972.005 $\mathrm{H} 673$ consulares de Francia", Historia Mexicana, vol. 19, núm. 2, oct.-dic., 1969, México, El Colegio de México, p. 302-308.

Este artículo es una aportación al conocimiento de las fuentes para la historia diplomática de México y Francia, y dentro de ella hay una parte importante que se refiere a la península de Yucatán y, concretamente, a lo que es hoy Quintana Roo. El artículo aporta referencias sobre correspondencia diplomática y memorias y documentos que tratan temas como la guerra de Castas, la lucha política entre Yucatán y Campeche, los conflictos entre Inglaterra, Belice y Yucatán desde 1836, etcétera.

COLMEX Pérez-Aanta, Ma. Carmen, et al., La frontera sur de

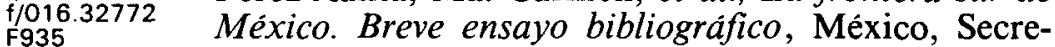
taría de Relaciones Exteriores, Instituto Mexicano "Matías Romero" de Estudios Diplomáticos, 1976, 34 h.

Importante investigación pionera en lo que se refiere a la bibliografía de la frontera sur de México, incluyendo los estados mexicanos de Chiapas, Campeche y Quintana Roo, y los países vecinos de Guatemala y Belice. Incluye libros, tesis, folletos y datos de los legajos y documentos que al respecto se encuentran en el Archivo "Genaro Estrada" de la Secretaría de Relaciones Exteriores. 
Woodward, Ralph Lee, comp., Belize, S. Barbara, Calif., Clio, 1980 (World Bibliography Series, 21), 229 p.

Bibliografía de Belice muy extensa y completa, que agrupa las entradas por temas. Además, proporciona excelentes comentarios de cada obra y referencias cruzadas. Una de las mejores y más completas bibliografias sobre Belice.

\section{BIBLIOTECAS CONSULTADAS}

BCWDC Biblioteca del Congreso, Washington, D. C.

LAC/UTA Latin American Collection, University of Texas, Austin, Texas.

LAL/TU Latin American Library, Tulane University, Nueva Orleáns, La.

BNAL Biblioteca Nacional, México, D. F.

INAH Biblioteca de Antropología e Historia, México, D. F.

COLMEX Biblioteca Daniel Cosío Villegas, El Colegio de México, México, D. F.

BIM Biblioteca del Instituto de Investigaciones Dr. José Ma. Luis Mora, México, D. F.

CIESAS Centro de Investigaciones y Estudios Superiores en Antropología Social, México, D. F.

HNAL Hemeroteca Nacional, México, D. F.

BGMCP Biblioteca General Manuel Cepeda Peraza, Mérida, Yucatán.

BABV Biblioteca de Alfredo Barrera Vázquez, Mérida, Yucatán.

BEWA Biblioteca de E. Wyllis Andrews, Mérida, Yucatán.

IQC Instituto Quintanarroense de Cultura, Chetumal, Quintana Roo.

BCCC Biblioteca del Cronista de Ciudad Chetumal, Chetumal, Quintana Roo.

BJRG Biblioteca Javier Rojo Gómez, Chetumal, Quintana Roo.

BALM Biblioteca Adolfo López Mateos, Chetumal, Quintana Roo.

B del A Biblioteca del Autor. 